\title{
An Evaluation of Existing Models Describing the Migration of Additives in Polymers
}

1. C. Sanchez, S. S. Chang, F. L. McCrackin and L. E. Smith

Polymer Science \& Standards Division Center for Material Science National Bureau of Standards Washington, D.C. 20234

Semi-annual Report for Period

September 1, 1977 - March 30, 1978

Issued July 1978

Prepared for

Bureau of Foods

Food and Drug Administration

Washington, D.C. 20201

Interagency Reimbursable Agreement 

1. C. Sanchez, S. S. Chang, F. L. MicCrackin and L. E. Smith

Polymer Science \& Standards Division

Center for Material Science

National Bureau of Standards

Washington, D.C. 20234

Semi-annual Report for Period

Soptember 1, 1977 - March 30, 1978

Issued July 1978

Prepared for

Bureau of Foods

Food and Drug Administration

Washington, D.C. 20201

Interagency Reimbursable Agreement

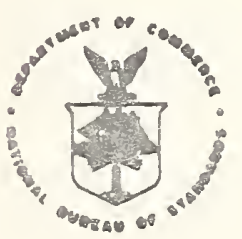

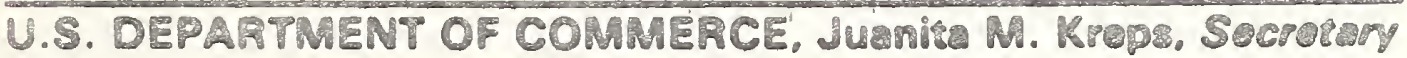

Dr. Sidney Haman. Under Soeretany

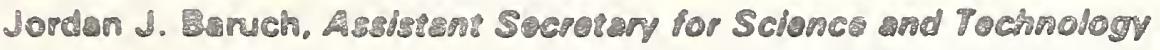

NAPIONAL BUREAU OF STANDAROS. Emel Ambler. OHRetor 



\title{
AN EVALUATION OF EXISTING MODELS DESCRIBING THE MIGRATION OF ADDITIVES IN POLYMERS
}

\author{
I. C. Sanchez \\ S. S. Chang \\ F. L. McCrackin \\ L. E. Smith
}
Report to: Bureau of Foods
Food and Drug Administration

Covering the period September 1, 1977

to

March 30, 1978 

The objective of this work is the development of mathematical models that describe the migration of a variety of small molecules in polymers that have applications in food contact uses. In the most general cases, these models will be able to predict the amount of additive migration given any particular time and temperature history. These models can serve as the technical basis for more efficient regulatory methods under existing Erameworks or in the design and implementation of new indirect additive regulations or policy.

The existing data on aditive migration applicable to food contact uses have been surveyea and organized for reference. Existing models describing additive migration into foodsimulating solvents have been surveyed and evaluated. prom these considerations four main conclusions can be drawn:

1) At a given temperature above the glass transition of the polymer, diffusion in the polymer is invariably proportional to the concentration gradient of the diffusing species. The concentration gradient is the rate of change in concentration with aistance in the polymer.

2) Diffusion in polymers below their glass transition is complex and difficult to generalize.

3) Above the glass transition temperature, the temperature dependence of diffusion is primarily detemined by the properties of the polymer and relatively independenc of the size and shape of the diffusant.

4) The temperature dependence of the diffusion is strong and non-Arrhenius. This means that a plot of the logarithum of the diffusion constant versus the inverse of the absolute temperature will generally be non-linear.

To model migration of minor constituents from a polymeric film to a food simulating solvent requires knowleage of (I) the equilibrium distribution of a migrant between polymer and solvent phases, $i . e .$, the distribution or partition coefficient $K$ and (2) the diffusion coefficient $D$ of the migrant in the polymer. This is the minimum amount of information required to describe polymer/migrant/solvent system. For a polymer at a temperature above its glass transition temperature, knowledge of $K$ and $D$ allows one to calculate migration as a function of time and as a Eunction of temperature if the temperature variation of $K$ and $D$ are also known. 
We have shown that the distribution coefficient is related to the migrants" chemical potential in the polymer and solvent and have demonstrated how $K$ and its temperature dependence can be calculated using recently developed theories of the chemical potential. Our preliminary calculations have been very encouraging. Additionally, $\mathrm{K}$ is amenable to experimental determination by utilization of gas chromatographic techniques.

Existing theories of the diffusion coefficient can be characterized as being correlative rather than predictive. We have formulated a new theory for $D$ which promises to be more predictive than existing theories. This new theory is based on the themodynamic theory of Eluctuations and depends on: (1) the shape and size of the diffusant, (2) the polymerdiffusant intermolecular interactions, and (3) the isothermal compressibility of the polymer. 
INTRODUCTION • . . . . . . . . . . . . . . . . 1

SURVEY OF MIGRATION DATA APPLICABLE TO FOODCONTACT USES . . . . . . . . . . . . . . . . 3

Introduction . . . . . . . . . . . . 3

Key to Abbreviations . . . . . . . . . 4 4

Ordered Index to Available Data . . . . . . 7

Literature References . . . . . . . . . 15

REVIEW AND EVALUATION OF AVAILABLE MIGRATION

MODELS • • • • . . . . . . . . . . 33

Introduction ............... 33

Distribution Coefficients . . . . . . . . 34

Diffusion Constants . . . . . . . . . . 42

General properties . . . . . . . 42

Diffusion above Tg . . . . . . . . 44

Diffusion below Tg . . . . . . . . . . . . . . . . . . . . . 47
References . . . 53

PREIIMINARY CLASSIFICATION OF ADDITIVE TYPES • . . 55 



\section{INTRODUCTION}

The effective regulation of indirect food additives arising from the migration of substances from plastic packaging materials involves three main technical questions:

1) What substances are present in the packaging material that can migrate into foods?

2) To what extent and at what rate can these substances be reasonably expected to migrate into the food?

3) What are the physiologic consequences of the ingestion of these quantities of these substances by the public?

The first of these questions can generally be answered by consideration of the synthesis and Fabrication steps of the packaging material supported by straightforward analytical methods. The third question is a complex toxicological problem which at present can only be answered with case by case cesting and even then is subject to considerable debate. The second question, however, is a measurement problem capable of general resolution and is the subject of this FDA-sponsored work.

The objective of this work is the development of mathematical models that describe the migration of a variety of small molecules in polymers that have applications in Eood contact uses. In the most general cases, these models will be able to predict the amount of additive migration given any particular time and temperature history. The models will be designed to require a minimum of laboratory data determined for the particular polymer-migrant system.

These models will serve several purposes. They can serve as a basis for the classification of polymers and additives into groups with similar migration behavior for regulatory purposes. They can reduce or eliminate the need for extensive extraction data to qualify new polymer-additive systems for food contact uses. For example, a change in a packaging process 
requiring a higher filling temperature could be considered on the basis of an extrapolation from existing data without the need for additional laboratory work.

Physical models of migration can allow a relatively rapid estimate of maximum exposure of the public to any aiven additive or additive type. These estimates can guide public policy and provide a quantitative basis for toxicological assessments of risk. Finally, physical models or description of migration behavior can provide the technical information for a comprehensive review or adjustment of the total regulatory framework covering indirect food additives.

The first steps in the development and assessment of such models are given in this report. The first section presents a preliminary survey of migration data appiicabie to food contact situations that are available in the current literature. The second section surveys available models describing migration and evaluates their present and potential utility. 


\section{INTRODUCTION}

The following literature survey collects and organizes available data on migration rates of low molecular weight species from polymeric matrices that have primary applicability to food contact situations. Only data that apply to food contact situations have been included. References that are useful in formulating and testing general models of migration will be added as the need arises. References prior to 1970 are also not explicitly included as these papers are adequately referenced in the cited, later work.

The ordered index is sorted first by type of polymer. then by the nature of the migrating species, and then by solvent. The abbreviations used are explained in the Eoilowing section. The remarks primarily refer to the type of data presented and the time and temperature interval for which data are available. 


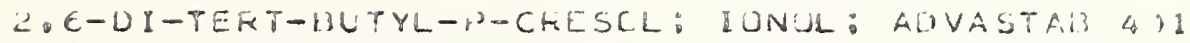

DINCNYL PHTHALATE

DIOCTYL PHTHALATE

DIDCTYL TIN CCNPJUNDS

N-COTR IACCTANE

OIDOOECYL- $3.3^{\circ}$-THICPRCPIONATE

FCFMALCEHYDE

2-HYOROXY-4-12 - ETHYLHEXYL 1-OXYBEN LOHHENORE: DASTIZ 242

2-HYOROXY-4-METHOXYBENZCPHENONE: UV ABSORAER MUB: ADVASTAH 45 2-HYOKCXY-4-OCTCXYGENZOPFENCNE: AUVASTAB 4E: CYASOKB UV5Z1 N-HEXACECANE

MAGNESIUM STEAFATË METHYL METHACRYL TE

2.2-METHYLENE-BIS-84-METHYL-O-TERT-BUTYLPHENOL: 2246 METHYL TIN CENPCUNOS

MICFCWAX

4-NITRC-4'-AMINCAZOBEAZENE

N-CCTACECYL-DIETHANUL AMINE

N-CCTADECYL-B-640-HYDROXY-3.50-OI-T-6JTYLHHENYL PPRJPIJPATE PCLYADIPATE

LEAD

PFENUL

ALKYL FHYHALATES

ALKYL SULFONIC ACIO ESTERS

STYRENE

STEARIC ACID AMIDE

TIN CCMPCUNOS

DISTEAFY THICDIPROPIONATE: AOVASTAB PSBIZ: ANTLOXYDANS AS $S T P$ $T H C$ TCP

TEP

$T$ is

TRICFESCL. FMCSPAATE

TRIETHYL PHCSPHATE

TRIGLYCER IDES

TITARIUM DICXIDL

TRIS-(NCNYLPHENYL) PHCSPHATE: AUVASTAB TNPP

1. 3.5-TRIMETHYL-2. 4.6-TFIS(3.5-UI-T-BUTYL-4-HYULUXYEYENZYL)

VIAYL ACETATE

VINYL CHLCRIOE

PARAFFIN WAX

BENZENE: CHLOHLBHENENE: LITHYENE GLYCOL: ETHYL EHTEF: ETHANOA: A-AL.KANE

ZINC STEARATE 


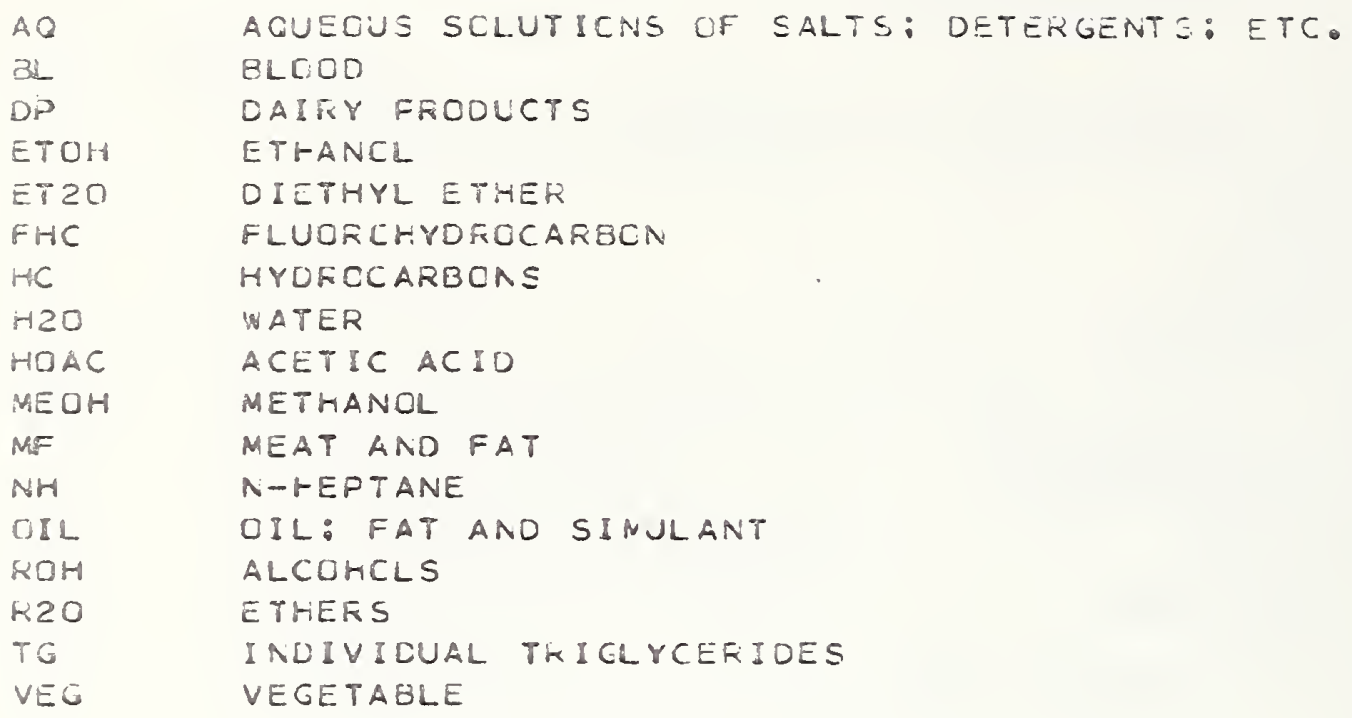

* * * * * METHCDS*****
CA CHEMICAL ANALYSIS
COLDR CCLCRIMETRY
GC GAS CHRCMATCGRAPHY
GM GRAVIMETRY
PHOTO PHCTCMETRY
POLAR PCLAREGRAPHY
RAD RADICANALYSIS
SECT SECTICNAL ANALYSIS
SPEC SPECTRCSCOPY
TLC THIN LAYER CHRCNATOFGFAPHY

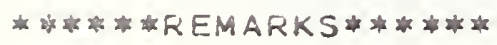

$A C$

$A P P$

CMT

$C P$

D

ENI

GR

H*

K

$M C$

NC

NKD

NS

NTT
ACTIVITY COEFFICIENT

APPARATUS/METHCO

CORRELATICN/MUDEL/THEORY

CONCENTRATICN GFAUIENT PRCFILE

DIFFUSION CCEFFICIENT

EXTRACT NOT IOENTIFIEC

GRAPHS

ACTIVATION ENEFGY

PARTITION COEFFICIENT

MIGRAAT CONCENTFATICN

AC CCMFOSITION

NO KINETIC DATA

NC SURFACE AREA INFORMATILN

NC TEMPERATURE OR TINE IAFCFMATION 
PHR PAKTS PER HUNUREU PARTS CF KESIN

RT

RCCM TEMPERATURE

SD

SORPTICN-DESORPTION

SECT

SOL

UNITS

SECTICNAL CBSEFVATICN

SCLUBILITY

C-CELCIUS: D-DAY: H-HOUR: M-MONTH: W-WEEK: Y-YEA

\section{ORDERED INDEX TO AVAILABLE DATA}

POL YMER MIGRANT SOLVENT METHCD

\begin{tabular}{|c|c|c|c|c|c|c|c|}
\hline$A B S$ & $A B C$ & ETCH & & $\mathrm{NKO}_{2}$ TO & $80 C / 70$ & 50 & \\
\hline$\triangle B S$ & $A B C$ & $\mathrm{H} 2 \mathrm{C}$ & & NKD. TO & $830 / 50$ & 50 & \\
\hline$A B S$ & Av & AO & & GE: RT/ & 702000 & & \\
\hline$A B S$ & $A N$ & $\mathrm{H} 2 \mathrm{O}$ & & GR: RT/ & TO 2000 & & \\
\hline$A B S$ & BST & ETOH & & NKD. TO & $83 C / 10$ & 50 & \\
\hline$A B S$ & BST & $\mathrm{H} 2 \mathrm{O}$ & & NKD. TO & $85 \mathrm{c} / \mathrm{TO}$ & 50 & . \\
\hline$A B S$ & $\mathbf{s}$ & AO & & GR: RT/ & TO 2000 & & \\
\hline ADS & s & ETOH & & NKD. TO & $80 C / 70$ & $5 D$ & \\
\hline$A B S$ & s & $\mathrm{H} 2 \mathrm{C}$ & & NKD. TO & $8 \nu \mathrm{C} / \mathrm{TO}$ & 50 & \\
\hline$A B S$ & $s$ & $\mathrm{H} 2 \mathrm{O}$ & & GK: RT/ & TO 2050 & & \\
\hline$\triangle B S$ & $x y z$ & & & INTER-PO & L YMER, & $A P P$. & $70 C / 70 \quad 13200$ \\
\hline$C A$ & $D C P$ & ET20 & GC & NKD. ro & $98 C / 70$ & 850 & \\
\hline CA & DOP & $H C$ & GC & NKD. TO & $98 \mathrm{C} / \mathrm{TO}$ & 100 & \\
\hline CA & DOP & OIL & GC & NKD, TO & $98 C / T 0$ & 100 & \\
\hline$C A$ & DOP & TG & GC & NKD, TO & $98 \mathrm{C} / \mathrm{TO}$ & 100 & \\
\hline$C A$ & $x y z$ & & & & & & \\
\hline$E / P$ & $M \times D$ & & & D & & & \\
\hline EPXR & & & . & CMT & & & \\
\hline$F P$ & HCHO & $H \approx C$ & & NKD. $\quad 0-9$ & $200 / 1-10$ & & \\
\hline MFR & $\mathrm{HCHO}$ & $\mathrm{H} 2 \mathrm{C}$ & & AKD & & & \\
\hline NR & ctcr & & & $D$ & & & . \\
\hline NR & $w A x$ & & & TO 2800 & & & \\
\hline NR & $x y z$ & & $G M$ & BLOOM & & & \\
\hline NR & $X Y Z$ & & & D.CMT. & SMEAR & & \\
\hline$P A$ & CO & ETOH & & $\mathrm{eSC/GH}$ & & & \\
\hline PA & $C D$ & ET2O & & $8 C C / 6 M$ & & & \\
\hline$P A$ & CD & H2C & & $80 C / 6 \mathrm{H}$ & & & . \\
\hline$P A$ & $C D$ & MOAC & & $80 \mathrm{C} / 6 \mathrm{H}$ & & & \\
\hline$P B D$ & $H X D$ & & & C. CMT & & & \\
\hline PBD & $R \times D$ & & & D. CMT. & SMEAR & & \\
\hline PBO & $H \times D$ & & & $D$ & & & \\
\hline PDMS & CTCT & & & $D$ & & & \\
\hline$P E$ & EHA & ET20 & GC & AKD, TO & 9BC/TO & 130 & \\
\hline PE & EKA & $\mathrm{HC}$ & ${ }^{\circ} \mathrm{GC}$ & AKD. TO & 38C/T & 200 & \\
\hline$P E$ & EHA & OIL & $G C$ & NKD. TO & $98 \mathrm{C} / \mathrm{T0}$ & 100 & \\
\hline$P E$ & EHA & PG & GC & AKD. TO & $98 \mathrm{C} / \mathrm{T}$ & 100 & \\
\hline$P E$ & $E P D$ & ETOH & & $45 c / 2 \cdot 10$ & $00.700 /$ & $2 \mathrm{H}_{0}$ & $100.121 \mathrm{C} / 0.5 \mathrm{H}$ \\
\hline PE & EPD & $\mathrm{H} 2 \mathrm{O}$ & & $45 C / 2.10$ & $00.70 \mathrm{Cl}$ & 214 & $130.121 \mathrm{C} / 0.5 \mathrm{H}$ \\
\hline PE & EPD & MOAC & & $45 c / 2.10$ & $0.720 /$ & $2 H_{0}$ & $1 . J \cdot 12: C / C .5 H$ \\
\hline PE & $B P D$ & OIL & & $45 c / 2.10$ & ID. $7 \mathrm{BC}$ & $2 \mathrm{H}_{0}$ & $1: 3,121 C / 0.5 \mathrm{H}$ \\
\hline PE & ETAC & ETCH & TLC & AKO. $45 C$ & $=1100$ & & \\
\hline$P E$ & ETAC & $H C$ & TLC & NKD. $45 C$ & $=/ 1 C D$ & - & \\
\hline$P E$ & ETAC & HC & & $G F: 40-6$ & $5 C / 706$ & 500 & \\
\hline PE & ETAC & $\mathrm{H} 2 \mathrm{O}$ & TLC & NKJ. $45 \mathrm{C}$ & $0 / 100$ & & \\
\hline
\end{tabular}

124

$22 \%$

149

34.4

124

124

$? \$ 4$

124

126

144

112 


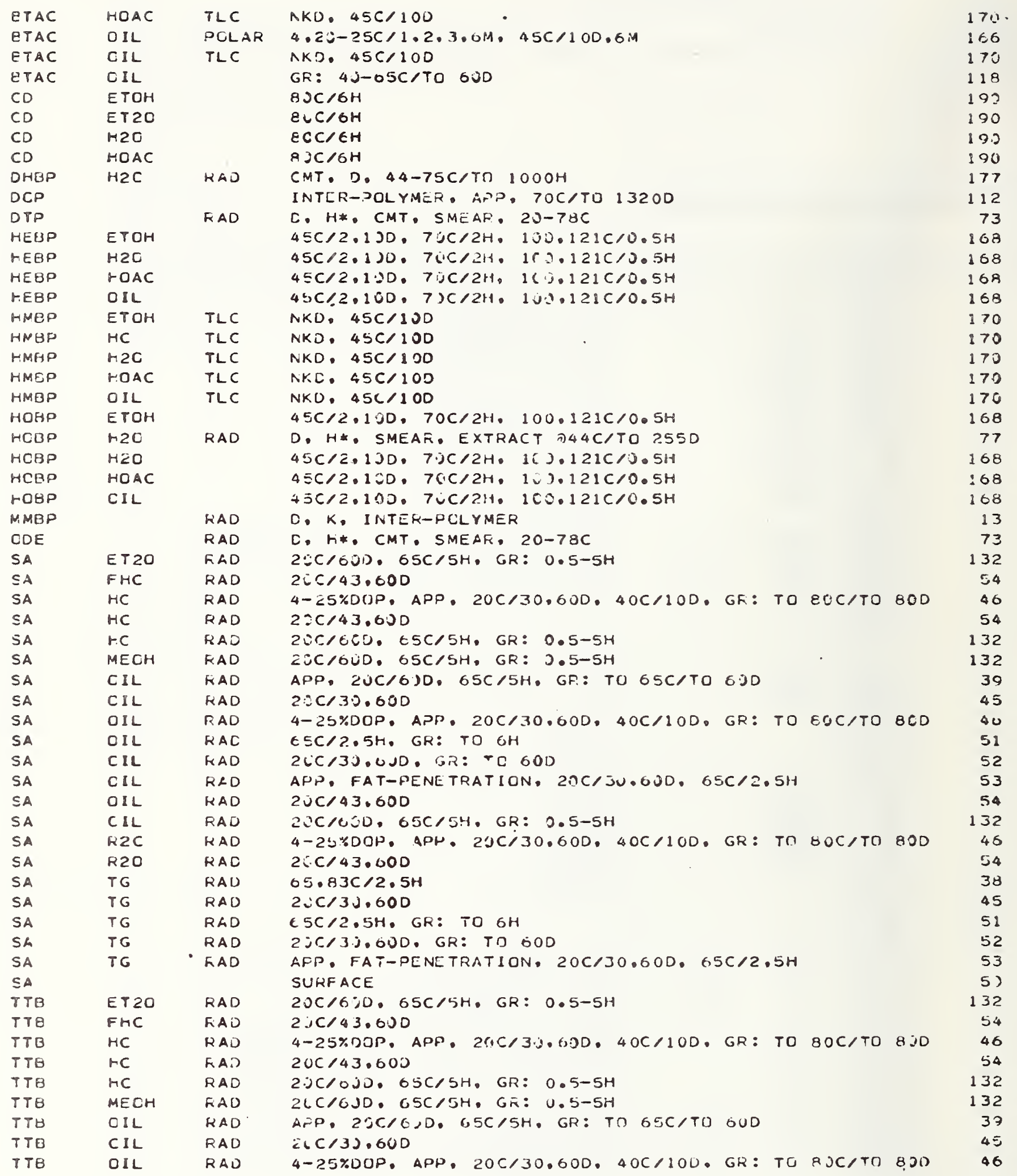




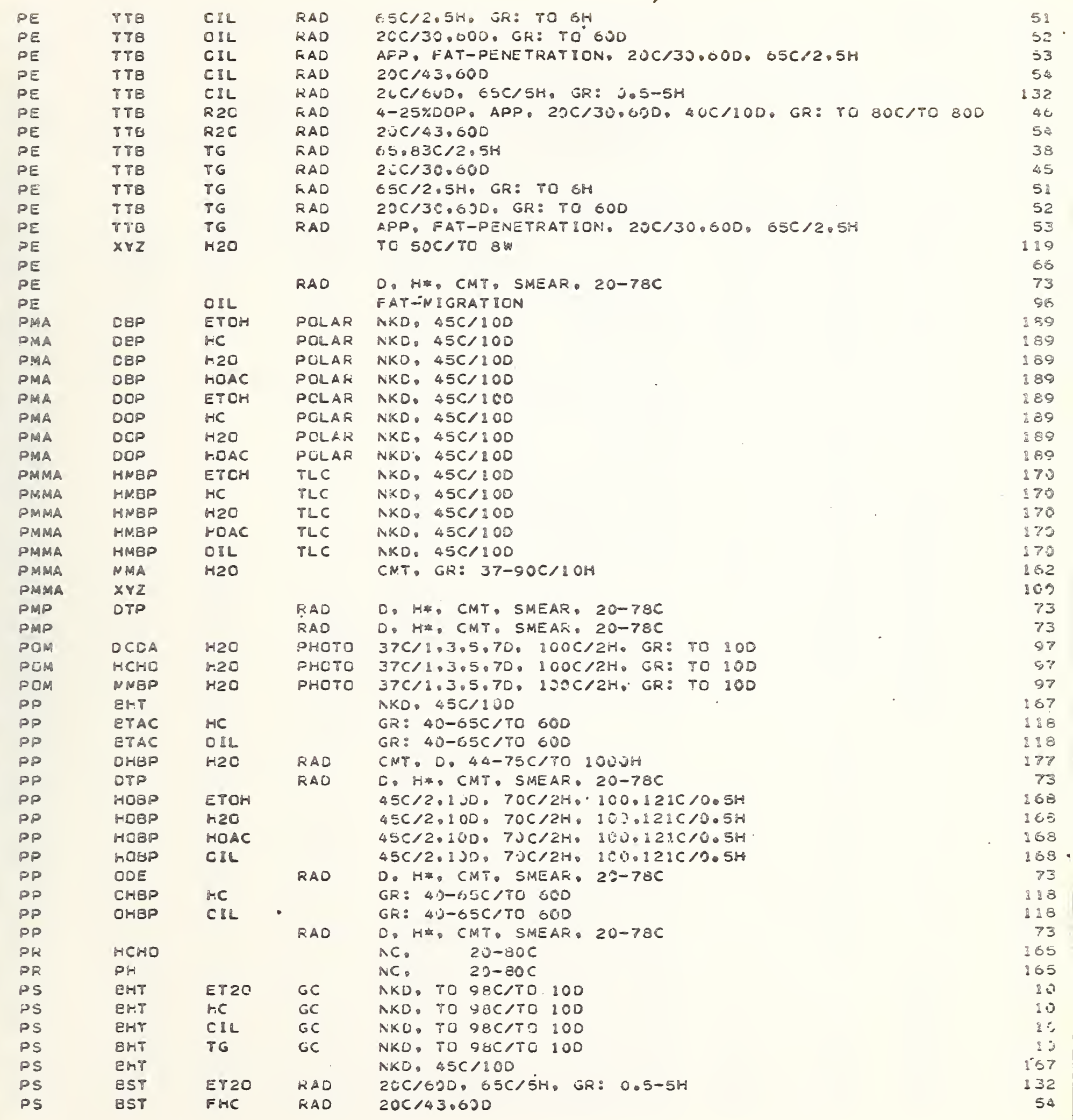




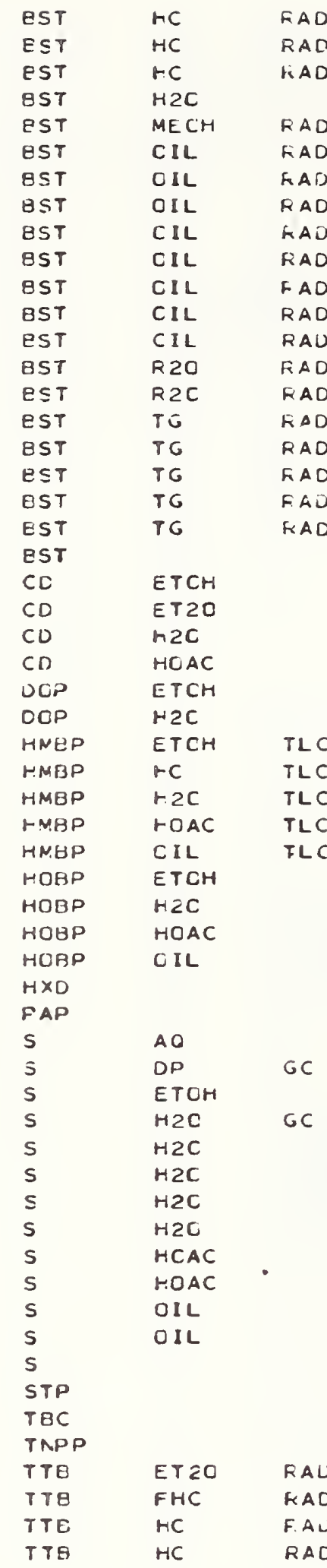

4-25\%0OP. APP, $200 / 30.600,40 C / 130$, GR: TD BOC/TO $8=0$ $2 \pm(<3,6) 0$ 


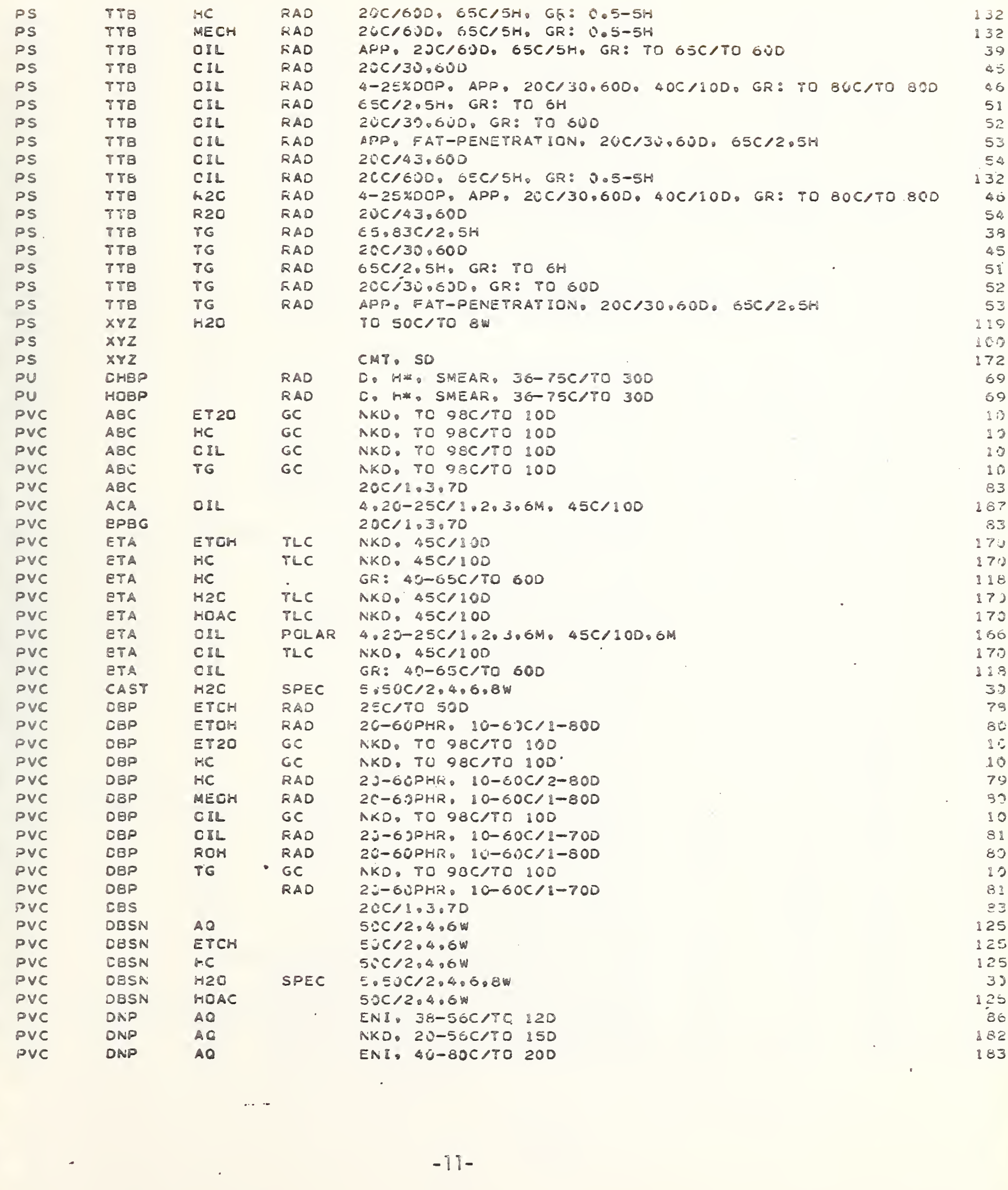




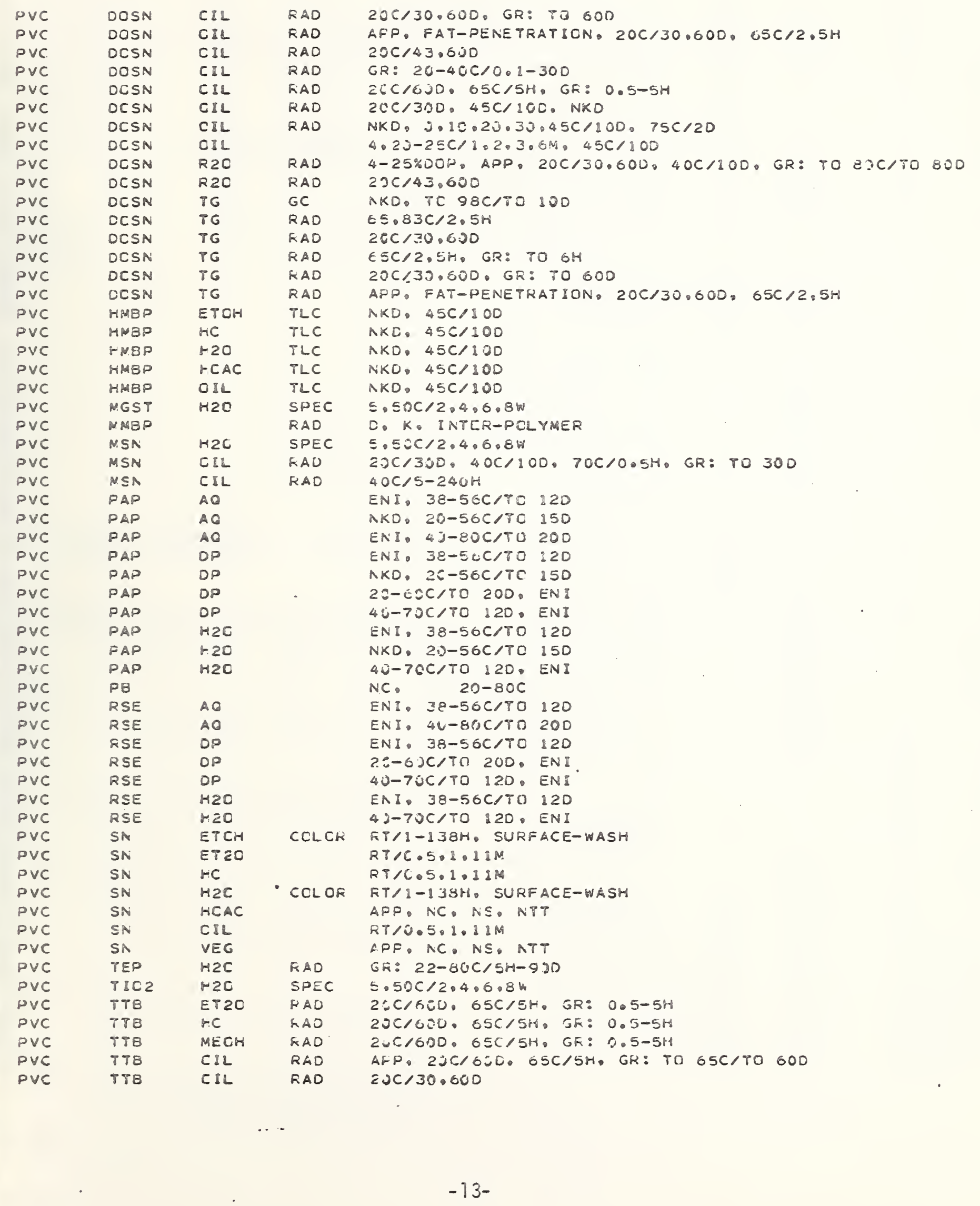




\begin{tabular}{|c|c|c|c|c|c|}
\hline PVC & TTB & CIL & RAD & GSC/2.5H, GR: TO $6 H$ & 51 \\
\hline PVC & TTE & CIL & KAD & $22 C / 32.600, G F:$ TO 600 & 52 \\
\hline PVC & TTB & CIL & RAD & APP, FAT-PENETRATION, $20 \mathrm{C} / 30.600,65 \mathrm{C} / 2.5 \mathrm{H}$ & 53 \\
\hline PVC & TTB & CIL & KAD & $20 \mathrm{C} / 60 \mathrm{D}, 65 \mathrm{C} / 5 \mathrm{H}, \mathrm{GR}: 0.5-5 \mathrm{H}$ & 132 \\
\hline$P \vee C$ & TTB & TG & FAD & $\epsilon 5.83 C / 2.5 H$ & 38 \\
\hline PVC & TTE & TG & FAD & $20 c / 30.600$ & 45 \\
\hline PVC & TTB & TG & RAD & $65 C / 2.5 H, G P: T D 6 H$ & 51 \\
\hline PVC & TTE & TG & FAD & $20 C / 30.60 D \cdot G R:$ rO 600 & 52 \\
\hline PVC & TTB & TG & FAD & ARP, FAT-PENETRATICN, $20 C / 3 \mathrm{C} .6000,6.5 \mathrm{C} / 2.5 \mathrm{H}$ & 53 \\
\hline PVC & ve & ETCH & GC & AS, $22 \mathrm{C} / 3.6 .9 .12 \mathrm{M}$, GR: TO $49 \mathrm{C} / \mathrm{TO} 1$ OY & 27 \\
\hline$P \vee C$ & ve & ETCH & GM & $S C L, S D, 30-90 C$ & 7 \\
\hline PVC & ve & ETOH & & GR: $23-7 C C / C .01-7200$ & 131 \\
\hline PVC & ve & r.c & GC & NS, $22 \mathrm{C} / 3.6 .9 .12 \mathrm{M}$, GK: TO $49 \mathrm{C} /$ TO 1 OY & 2.7 \\
\hline$P \vee C$ & ve & F.C & GC & K. $S / D$ & 116 \\
\hline PVC & ve & 1.20 & GC & NS, $22 \mathrm{C} / 3,6.9 .12 \mathrm{~A}$, GR: TO $49 \mathrm{C} / \mathrm{TO} 1$ OY & 27 \\
\hline PVC & ve & $\mathrm{r.2C}$ & GC & K. CMT, SO & 62 \\
\hline$P \vee C$ & ve & $\mathrm{H} 2 \mathrm{C}$ & GC & $K, S C, A C$ & 63 \\
\hline PVC & ve & $r 2 \mathrm{C}$ & GC & $K_{0} \leq 10$ & 116 \\
\hline PVC & ve & $\mathrm{H} 2 \mathrm{C}$ & GM & $\mathrm{SCL}, \mathrm{SO}, 30-90 \mathrm{C}$ & 7 \\
\hline PVC & ve & $\mathrm{H} 2 \mathrm{C}$ & & $M C \cdot 23 C / 1-1800$ & 5 \\
\hline PVC & ve & $\mathrm{H} 2 \mathrm{C}$ & & GR: $23-7 C C / 0.01-7200$ & 131 \\
\hline PVC & ve & H.OAC & GC & $N S, 22 C / 3.6 .9 .12 M, G R:$ TO $49 C / T O$ IOY & 27 \\
\hline PVC & ve & MOAC & GC & K. SO, AC & 63 \\
\hline PVC & ve & hOAC & & $G R: 23-70 C / 0 . C 1-7200$ & 131 \\
\hline PVC & ve & OIL & GC & $40 \mathrm{C} / 10.200, \mathrm{KT} / 35 \mathrm{D}, \mathrm{GR}:$ TO $1600, \mathrm{CP}$ & 93 \\
\hline PVC & ve & OIL & GC & NS, $22 C / 3.6 .9 .12 M$, GR: TO $49 \mathrm{C} /$ TO 1 or & 27 \\
\hline PVC & ve & CIL & GC & $K \cdot C M T, S D$ & 62 \\
\hline$P \vee C$ & ve & CIL & GC & $k \cdot 5 / 0$ & 116 \\
\hline PVC & ve & OIL & & GR: $23-70 \mathrm{C} / \mathrm{C} \cdot \mathrm{C} 1-7200$ & 131 \\
\hline PVC & ve & & GC & A1R, MOOEL, GR: TO $38 \mathrm{C} / T O 300$ & 26 \\
\hline$P \vee C$ & ve & & GM & C. SO, CMT. $20-90 \mathrm{C}$ & 9 \\
\hline PVC & ZNST & $\mathrm{H} 2 \mathrm{C}$ & FAD & $G R: 22-80 C / 5 H-900$ & 12 \\
\hline PVC & & MF & GC & $4 C / 1,2,8,40$ & 28 \\
\hline$P \vee D C$ & DCP & OIL & & AFP, CMT, SECT, CP, FAT-MIGKATION, $40 \mathrm{C} / 1.2 .4 .9 .16 .250$ & 130 \\
\hline PVDC & & ETCH & & $G R: 23-70 C / 0.01-7200$ & 131 \\
\hline PVOC & & $\mathrm{H} 2 \mathrm{C}$ & & GR: $2 \equiv-70 \mathrm{C} / 2.01-7200$ & 131 \\
\hline PVDC & & HOAC & & GR: $23-7 U ̈ C / E .01-7200$ & 131 \\
\hline$P \vee D C$ & & CIL & & $G R: 23-70 \mathrm{C} / 0.01-7200$ & 131 \\
\hline SAN & AN & $\mathrm{ETCH}$ & & GR: $23-7) C / 0.01-7200$ & 131 \\
\hline SAN & AN & $\mathrm{r} .2 \mathrm{C}$ & & $G R: 23-7 C C / C \cdot 01-7200$ & 131 \\
\hline SAN & An & HCAC & & $G R: 23-70 C / C \cdot C \cdot 1-720 D$ & 131 \\
\hline SAN & AN & OIL & & $G R: 23-70 . C / 0.01-7200$ & 131 \\
\hline$S B R$ & Bco & & & D & 141 \\
\hline SER & $H \times D$ & & & C. CMT & 139 \\
\hline SBR & Mw & & GM & BLCOM & 158 \\
\hline SBR & wax & & & TO 2800 & 19 \\
\hline$V / A P B$ & VAC & $\mathrm{H} 2 \mathrm{C}$ & & $6 U C / 1 H, N K D$ & 22 \\
\hline$V / A P B$ & ve & ETCH & • & & 14 \\
\hline$V / A P B$ & ve & $\mathrm{m} 2 \mathrm{C}$ & & & 14 \\
\hline PAN & AN & $\mathrm{H} 2 \mathrm{C}$ & GC & K. SO, AC & 63 \\
\hline PAN & AN & FOAC & GC & K. SD, $A C$ & 63 \\
\hline$P \vee C / \triangle B S$ & AN & ETCH & PLLAR & $A K D, E T / 4 D$ & 95 \\
\hline PVC/ABS & AN & $\mathrm{H} 2 \mathrm{C}$ & PCLAK & $A K C, R T / 4 D$ & 95 \\
\hline PVC/ABS & AN & MOAC & PCLAK & NKD, RT/4D & 95 \\
\hline PVC/ABS & An & CIL & PCLAR & $A K C, R T / 4 D$ & .95 \\
\hline$P \vee C / A B S$ & EST & ETOH & PCLAR & NKD, RT/40 & 95 \\
\hline PVC/ABS & EST & $\mathrm{H}_{2} \mathrm{C}$ & PCLAR & $A K C, R T / 4 D$ & 95 \\
\hline PVC/ABS & EST & FOAC & PCLAR & $A K D, R T / 4 D$ & 95 \\
\hline
\end{tabular}




\begin{tabular}{|c|c|c|c|c|c|}
\hline PVC/ABS & ESt & $C \mathbb{L}$ & PCLAR & NKD, RT/4D & \\
\hline PVC/ABS & DCP & ETCH & PCLAF & $A K C, R T / \triangle D$ & \\
\hline PVC/AAS & DOP & $H 2 C$ & POLAK & AKC, RT/ $R D$ & \\
\hline PVC/ABS & OCP & MCAC & PCLAK & $2 \times 0, R T / 40$ & \\
\hline PVC/ABS & DOP & CIL & PCLAR & NKC, RT $/ 40$ & \\
\hline PVC/ABS & s & ETCH & PCLAR & NKD. RT/ 40 & \\
\hline PVC/ABS & s & $+2 C$ & PCLAR & AKC. RT/40 & \\
\hline PVC/ABS & $s$ & H.CAC & POLAK & NKD. RT/4D & \\
\hline PVC/ABS & 5 & CIL & PCLAR & AKC, RT/4D & \\
\hline PAT & $x \vee z$ & CIL & RAD & $A P P, 40 C / 100$ & \\
\hline PES & $x y z$ & $\mathrm{H} 2 \mathrm{O}$ & & TC $50 \mathrm{C} / 70 \mathrm{BW}$ & \\
\hline$A B S / M A$ & & ETEH & & $35-65 C / 1-70^{\circ}$ & NKD \\
\hline$A B S / M A$ & & $H 20$ & & $39-65 C / 1-7 D$ & NKD \\
\hline$A B S / M A$ & & MOAC & & $3 s-65 C / 1-7 c$ & NKD \\
\hline \multirow[t]{2}{*}{ ABS/MA } & & & & $\begin{array}{l}39-65 C / 1-70 . \\
A P D\end{array}$ & NKD \\
\hline & & & & $A P P$ & \\
\hline
\end{tabular}

\section{LITERATURE REFERENCE}

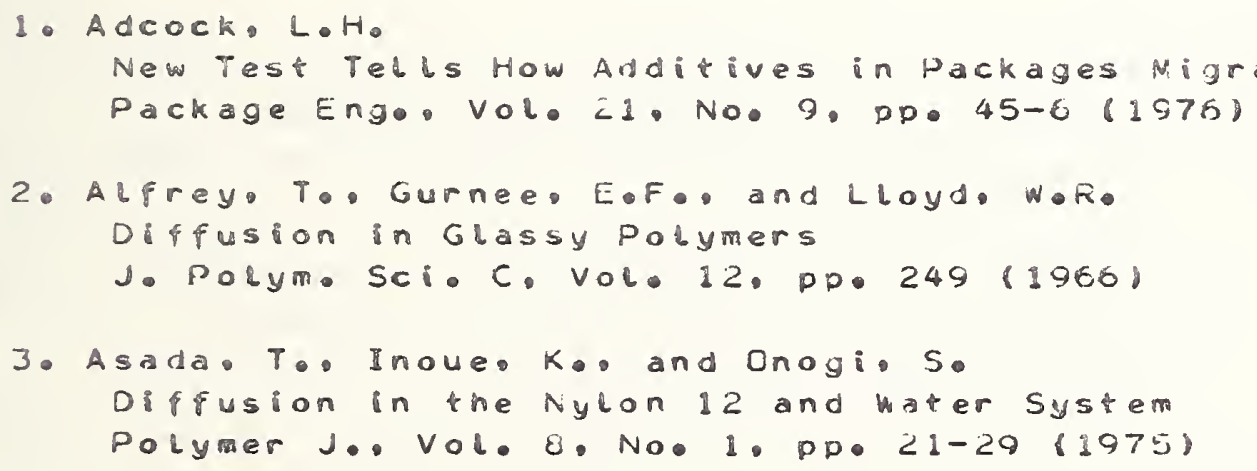

4. Bagdonaite. V.A.. and Yushkevichyute. S.S. Migration of Antioxidants between Polyethylene and PVC Plast. Massy. No. 9. PD. 53 (1975): Intl. Polye Scio Technol. Vol. 3. No. 2. PP. $70(1576)$

5. Banzer. J.D.

The Migration of Vinyl Chloride Monomer from pVI Pipe into water Soc. Plaste Eng. AATEC, Nov, 1977, pD. 3-34

6. Bent. H.A. and Pinsky.j. Theoretical Investigation of the Mechanism of Transfer of Materlals through Polyethylene

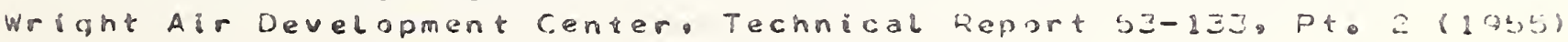


7. Berens. A.f.

The Solubility of vinyl Chloride in polylvinyl chloridel

Polymer Preprints. Vol. 15. Fp. 157 (1974)

8. Berens. A.R.

The Diffusion of Vinyl Chloride in Polylvingl chloridel

Polymer Preprints. Vol. 15. Pp. 203 (1974)

9. Berens. A.Fo. and Caniels, C.A.

Prediction of Vinyl Chloride Nonomer Migration from Rigid PVC Pipe Polym. Eng. Sci.. Vol. 16. No. 5. pp. 52 (1976)

10. Bergner. K.G. and Berg. Ho

Migration of Addatives from plastics in Triglycerides Compared with their Extractability by Organic Solvents

Dtsche Lebensmo-Findscho. Vol. 68. No.9, pp. 282-8 (1572)

11. Bethune. Jol.

Directed Transport of Monomer-Single Polymer Systemse Comparison of the Countercurrent Analog and Asymptotic Approaches

J. Phys. Chem. Vol. 74, No. 22, pp. 3937-45(1970)

12. Bloom. P.J.

Contribution to the Investigation into the Migration into Liquic

Foods of Auxiliary substances Used in Plastics Manufacturing Processing. Part II. Migration of Auxiliary Substances of Polylvinyl Chloridel into Crinking water

Disch. Lebensm.-Rundscho, Vol. 72, No. E. pp. 194-7)(1976)

23. Bobrouskaya, T. So. Markelov, M.A., and Semenenko, E.I.

Migration of Dioctyl Phthalate from Plasticised PVC into Water Plast. Massy. No. 4. pp. 5e (1574): Intl. Polym. Sci. Technol.. Vol. 1. No. 7, pp. 10 (1974)

14. Boikova. Zoke. and Petrova. L.I.

Migration of Vinyl Acetate frcm Copolymers isased on it

Plaste Massy. No. 12. pp. 43 (1976): Intl. Polym. Sci. Technol.. Vol. 4. No. 5, pp. 35 (1977)

15. Booher. T.F.o and Stringer. C.D.

study of Additive Migration from Films to food by l 4 C - Labling

ACS Abstr. Div. Crg. Coat. Plast., Vol. 152, pr, T22 (1960)

16. Botre, Co, DoAntoni, Lo. Nemoli, Ao, and Pallotti, Go

Chemical. Technicopharmaceutical and Legislative Aspects on the

Transfusion Elood and its Components. Note. II Extraction of

Plasticizers from Blood in the Poly(Vinyl Chloride) Containers

Rass. Chim.. Vol. 27 . No. 5, pp. 245-8 (1575)

17. Brlt. Hlast. Fed. and Brit. Ind. Biolo Res. Assoc.

PLastics for Food Contact Applications. A Code of practice for

Safety in Use

London, pp. 54 ( $15 \in 9$ )

18. Broitman. A. Ya.. Putilina, L. V., and Podvalonaya. E. K.

Toxlcolgy of Vinyl Acetate-Vingl Pyrrolidone Copolymers

Plast. Massy. No. 12, pp.4E (1976): Intl. Polym. Sci. technol.., Vol. 4, No. O. p. 50 (1977) 
19. Brown. D. W. and Loweryo FoE.

Herny's Law and Diffusion Constants of Vinyl Chloride in

Polyluinyl chloridel at High Temperature

J. Polyme Sci.. Polym. Chem. Secto, Vol. 15, pp.2623-33 (1977)

20. Bruck, C.G. vom. Eckert, W. F. and fudolph. F. B.

Migration of Vinyl from PVC Packaging

Fette. Seifen. Anstrichem. Vol. 78, No. 8, pDe 334-7 (1976)

Inth. Polym. Sci. Technol.. Vol. 3, No. 10, pp. 163 (1976)

21. Bruck, CoG. Vom, Figge. Ko. Fiater, Ho and wolfo Vo

Migration of Plastics-processing Adjuvant substances from Films

into Liquid and Solid fats and Simulants. Ix. Results of

Previous Extraction and Migration Studies

Dtsch. Lebensme-Rundsche, Vol, 67. No. 12, pp. 444-5. (1971)

22. Chalyukh. A.E.

Diffusion of Monomers in Polymers

Vysokomol. Soedin.. Ser. 8. Vol. 17. No. 3. pp. 215-13 (1975)

23. Chantrey. Go, and Fattee, I.D.

Influence of Polymer and uye Characteristics on Diffusion in Aylon 66

J. Appl. Pobym. Sci.. Vol, 18. No. 1. pp. 93-193 (1974)

24. Code of Federal Regulations. Tithe 21. Food and Drugs

Part 175. Indirect Food Adeltives: Adhesive Coatings and Components

Part 176. Indirect Food Additives: Paper and Paperboard Components

Part 177. Indirect Food Additives: Polymers

Aprit 1. 1977

25. Chernova. ToV.

Hygienic Evaluation of SNP-2P Polystyrene Containers Intended for Packaging Foodstuffs

Vopr. Pitan.. Vol. 30. No. 5. pp. 56-5\& (1971)

26. Crider. LoB.o OMara. MoMo. and Bowles, Fol.

A Model for the Diffusion of Vinyl Cnloride Monomer from PVC

Under various Conditions of storage

Soc. Plast. Eng. NATEC. Nov, 1977, 195-9

27. Daniels, G.A. and Proctor, D.E.

VCM (Vinyl Chloride Monomer) Extraction from PVC Bottles

Mod. Packog., Vol. 4., No. 4. pp. 45-8 (1975)

28. Daun. He. and Gibert. S.G.

Migration of Plasticizers from Polyluinyl chloride) Packaging Films

to Meat

J. Food scio, Vol, 42. No. 2, ppo 501-2 (1977)

29. Davies, joT.

Migration of styrene Monomer from Packaging Materials in Foodo

Experimental Verification of a Theoretical Model

J. Food Technol.. Vol. 9. No. 3. pp. 275-83 199741

30. Dietzo GoR.. Banzer. J.0.0 and Miller. E.M.

Water Extraction of Additives from PVC Pipe 
Soc. Plaste Enge AATEC. NOV. 1977. pP. 25-9

31. Dotreppe-Grisard. A.

Control of the Migration of Adjuvants of Plastic Materials in Food Liquids

Trib. Cebedeau (Cent. Belge Etude Loc. Eauxi. Vol. P5. No. 341. $p p .198-201(1972)$

32. Dotsenko. VoA.o and shiba, $V_{0} V_{0}$

Methods for a Sanitary-Chemical Evaluation of Polymeric Materials ant Products Made from them in Contact with Foods and Drinks

Gig. Sanito. Vol. 19. ppo Suj-2 (1972)

33. Downes. Towo

The Mechanism of the Migration of organotin Stabilizer from Polylvinyl chloridel into Containing Nedia

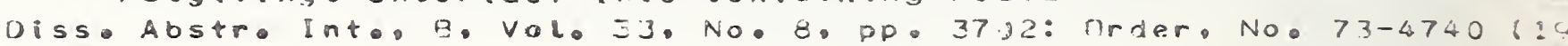

34. Downes. Tou. and Gibbert. S.G.

The Effect of Surface Treatments on the Migration of organctin Stabilizer from Polyruingl chboridel Films to contactingliquid Media

Dtsch. Lebensm.-Rundsch.. Vol. 71. No. 12. ppo 4?2-425 (2075:

35. Easterling. R.E. Johnson. Eo. and Napier. E. to. Jro

Plasma Extraction of Plasticizers from Meoical urate Polylvinyt chloridel Tubing

Proce Soc. Exp. Biol. ked., Vol. 247. No. 2.pp.572-4(1974)

36. Evstatieva. M.

Migration of Some Azo Cyes from Prepared Polymer Materials

Knige Zdraveopazo. Vol. 16, No. 5, po. 479-82 (1973)

37. FDA Guidelines for Chem istry and Technoloyy. fequirements of Food Adyitives Petitions

Bureau of Science. FoA. HEW (August 1366)

38. Figge, Ko

Migration of Processing Aids from PLastic Film into Food Fats Kunststoffe. Vol. El. No. 11. pp.832-8(1971)

39. Fisge, Ko

Migration of Additives from Plastic Films into Edible Dils and Fat simulants

Food Cosmet. Toxicolo. Vol. 10. No.6.pp. 815-28 (1972)

40. Figge. K.

Determination of Total Migration from plastics-packaging Edible Fasts Using a Carbon-14-Labeled Fat simulant Materials Food Cosmet. Toxicolo. Vob. I1. No. O. Pp. 363-74 (1973)

41. Fige. K.

Method for the Determantion of the Total weight of All Components Migrating From Packaging Materiab into Edible Fats. the So-Calle. Total Migrate, Using Fat Simulant HB 307-(14)C Dtsch. Lebensm.-Rundsch. Vol. 69. No.7. pD. 253-7 619731 
Migration of Methyltin Thioglycobic Acid Esters frombigid PVC

Packagings into Fat-Containing Foods

verpack.-fundsch. Vol. 26. No. E. pp. 59-63(1075)

43. Figge. $K$.

Radioanalytic Method for Determining the Passaye of Packaying Ingredientsnto Foods

J. Radioanal. Chem.. Vol. 32. No.2. pp. 315-43(1976)

44. Figge. K. and aieber. wo D.

Migration of Methyltin Stabilizer Advastao TM isI FS from Riyid DVC into

Fat Simulant HB 3ü. I. Migration Betavior of Several ctabilizer

Components

verpack.-kiundsch., Vol. 26. No. 8. pp. 11-22 (1975)

45. Figge. K.. Eder. S.K. and Piater. Ho

Migration of Plastics Processing Additives out of Foits in Liqua

and Solid Fats as well as Simulants. Xi. synthetic Trighyceride

Mixture as General Fat Simulant

Otsch. Lebensmo-Rundsch. Vob. 68. Nos 1:. pp. تs9-57 (1972)

46. Figge. K.. and Koch. Jo

Effect of Some Variables on the Migration of Additives from

Plastics into Edible Fats

Food Cosmet. Toxicol.. Vol. 11. No.6.pp.975-983 (1973)

47. Figge. Ko. and koch. Jo

Determination of the Migration rate from plastics onto Nutritional fils

by means of a Carbon-14-Labeled Fat Simulating Ayent

Report AEC-Conf-7 $-461-1 . p 0.12(1973)$

48. Figge. K.. and koch, Je

Determination of the Total plastic packaging Components Migrating into

Edible Cil by Using a Carbon-14-Labeled Fint Simulant

Fette. Seifen. Anstrichm. Vol. 77. No. 5. Dp. 184-8 (1975)

49. Figge. K.. and Piater. H.

Methods of Migration and Extraction Studies with it 4 Clabeled

Additives. III. Migration of PLastic Additives from Filis into

Liquid and Solid Fats and Simulated Fats

otsch. Lebensm.-Rundsch. Vol. 67. No. 1. pp. S-15 (1971)

5). Figge. K.. and Fiater. H.

Migration of Adjunct Materials of PLastics Processing from Films

into Liquid and Solid Fats and Similar Substances. IV. Amounts

of Additives on the Test-film surfaces

otsch. Lebensm.-Fundsch.. Vol. 67. No.2. pp. 47-8 (1971)

51. Figge. K. and Fiater. H.

Migration of Adjuvants of Plastics Manufacturing from films into

Liquid and Solid Fats and Simulated Fatso. Ve Extraction and

Short-Term study iata

Otsch. Lebensm.-Rundsch.. Vol. 67. No.4. pp. 11.19 (1971)

52. Fiuge, K. and Piater. Mo

Migration of Auxiliary Materials from Plastic Films into Liquid

and Solid Fats or Fatlike Compounds. VI. Migration and

Long-Term Tests with Liquid Fats and Fatlike Materials 
Dtsch. Lebensw.-Rundsch. Vol. 67. No. 5. pp. 154-6181971)

53. Figge. Ko. and Fiber. H.

Migration of Adjuvants Used in Plastics Manufacture from Films. VII. Method and Results of Eutraction and Migration Experiments with Sobid Edible fats. Penetration of Adjuvants into Solid Fats otsch. Lebensm.-Rundsch. Vol. 67. No.7, pp. 235-42 (1971)

54. Figge. Ko. and Piater. Ho

Migration of Auxiliary Manutacturing Substances from Films into Liquid and Solid Fat and Simulants. X. Passage of Additives into N-Alkane and Ci-n-Alkane Ethers as wel as into other organic Liquics Dtsch. L.ebensm.-Rundsch. Vol, 68. No. 10, pp. 313-319 (1972)

55. Figge, Ko. and Zeman. A.

Migration of Tan Stabilizers from Unipasticized PVC Film into FatContalning Foods. X-kay Photoelectron-spectroscopic and Radioanalytical Examination of PVC Surfaces

Kunststoffe. Vol. 63. No. 8. pp. 543-50 (1973)

56. Franzke. Co. Unde. WoJ. ana woggon. H.

Migration of Antioxidants and stabilizers from plastic Packins into Edible Cil

Plaste Kautsch. Vob. 17. No.5.pP. 327-34 (197:)

57. Frawbey. J.P.

Toxicob. Evaluation of Migration of Food Additives

ACS abstr. Oive Crg. Coating Plast. Vol. 152. T23 (66)

5B. Frisch. Holo. Wang. ToTo. and Kwei. Tok.

Diffusion in Glassy Polymers II.

J. Polym. Sci. A. Vol. 2. No.7.pp. 37S (1969)

59. Fitize wo. and woggon. Ho

Migration of Carcinogenic hydrocarbons from Carbon-hLock Stabilized Plastics into Foods

2. Gesamte Hyg. Irre Grenzgeb.. Vol. 19. No. 5. pp. 346-352 (1973)

60. Ganeva. M.. and Radeva. M.

an Approach and Methods for Determination of Dye Migration from

Plastic Packing for Food Products

Khig. Zdrsveopazo. Vol. 19. No.3.pp. 281-5 (1976)

61. Gardner. Kol. and Mcnalby. G.M.

Morphology of Polypropylene in Relation to Dye Diffusion

J. Soce Dyers Colour. Vol. 93. No. 1. pp. 4-7(1977)

62. Gabert. S.G.

Migration of Minor Constituents from Food Packaging Materials

J. Food Sci.. Vol. 41. No. 4. pp. 955-8 (1976)

63. Gibert. S.Go. and Giacin. J.R.

Mgration of Indirect Food Additives from Plastic

Packaging Materials: Physical Chemistry Considerations

Soc. Plast. Eng. NATEC. NOV. 1977. DP. 35-30

64. Guricheva. Z.Go: Rudakoval, M.No 
Effect of the Composition of Polystyrene Plastics on Migration of LowNolecular-weight substances from them

Plast. Nossy. No. 12. DP. 3G-4L (1S70)

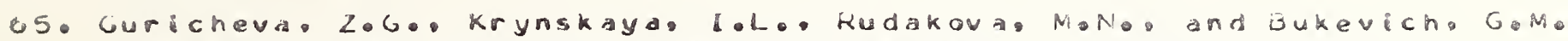

roxicclogical Evaluation of the Migration of phthalocyanine Blue

Dye from Folyethylene

Giq. Primen. Polim. Mater. Izdeli Nikh. No. 1. pp. 347-54 11969l

6.6. Gurlicheva. ZoG. Rotenberg. Vov.. and Snaulova. NoS.

Migration of Lake fied $\angle H E$ from righ-pressure Polyethylene

Gig. Sanit.. No. 6. PP. 94-5 (1974)

67. Gutsalyul. V.G. and Samosova. A. So

Migration of PLasticizers from Polylvinyl chborite) Plastics

into salt water Solution

Izv. Akad. Nauk kaz. SSR. Seroknim. No. 2. pp.9511962:

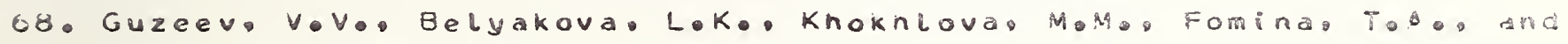

Lebedev. Vop.

Migration of Low-Molecular weight plasticizers from plasticized

Polytvinyl Chloride) into Polvethylene

Plast. Massy. No. 9. pp. 53- $=(1959)$

69. Hauserman. R.G.. and Johnson. N.

Diffusion of stabllizers in Polymers. III.

2. 4-Dinydroxybenzophenone and 2-Hydroxy-4-Cctoxybenzophenone in

Polyurethanes

J.Appl. Polym. Scl.. Vol. 29. No.9.pp. 2533-9 (1976)

70. Hem ing. D.F. Collins. JoDe. and Datyner. A.

The Effect of Competitive Adsorption on the Rate of Diffusion

J.Appl. Polym. Sci. Vol. 20.pp. 597-6!7 (1S?t)

71. Hibl. MoP.Lo. Millardo P.L.. and Cwen. Moj.

Migration phenomena in Silicone Modified Polystyrene

ACS Cive Crge Coat. Plast. Chem. Pap.. Vol. 34. No. 1. pp. 334-0 (1).4,

72. Ingle. G. W.

Quantitative spects of Nigration nf Food Alditives

ACS Crg. Coat. Plast. Chem.. Vol. 152. P21 (1966)

73. Jackson. R.A. Oldand. S.F.O. and Pajaczkowski. A.

Diffusion of Additives in Polyolefins

J. Appl. Polym. Sci.. Vol. 12. pp. 1297-1309 (1567)

74. Jaegers Roje

Extraction. Accumulation. and Metabolism of Phthalate Ester

Plasticizers from Polyivinyl Chlorlde) Medical oevices

Ph.D. Thesis. Johns Hopkins univo. ppo 194 (1971)

75. Jaeger. R.J.o and fiubin. Fol.

Migration of a Phthalate Ester plasticizer from polylvinyl

Chloridel Blood Bags into Stored Human 3lood and its Localization

in Huran Tissues

N. Engl. J. Med.. Vol. 287. No. 22, wp. 1114-8 19721

76. Jaeger. F.J.. and kubin. R.j. 
Plasticizers from Plastic Devices: Extraction. Metabolismo and Accurulation by tiological systems

Scrence. Vol. 179. No. 3956. Dp. 46.-2 (1979)

77. Johnson. Mo. and kestlake. J.F.

Diffusion of stabilizers in Polymerso II. 2-Hydroxy-4-Cctoxybenzophenone in Polyolefins

J.Appl. Polym. Scie. Vol. 19. No.6. Pp. 1745-5411975)

78. Kampouris. E。M.

Study of Plasticizer Migration by Radioactive Labeling

Rev. Gen. Caoutch. Plast. Vol. 52. No.4. FP. 283-92 (1975)

79. Kampouris, E。M。

Migration of Plasticizers into Petroleum Cils

Eure Polym. J.. Vol. 11. No. l6. pp.735-10619751

80. Kampouris. E.M.

Migration of Plasticizers from Poly(Vinyl Chloride) into Edible Uils

Poly. Enge Sci.. Vol. 16. No. 1. pp. 59-64 (1978)

81. Kampouris. E.M. Fegas. F.. Rokotas. S. Polychronikis. S. Pand Pantazc

Migration of PVC Plasticizers into Abconols

Polymer. Vol. 16. No. 11. Pp. 840-4 (1575)

82. Karel. Mo. ano wogan. GoNo

Migration of Substances from Flexible Containers for Heat Processed Foods

MIT Cambridge Civ. of Sponsored Res. Techo. Report No. 4. Jul I96z-jun 1963

83. Kataeva. SoE. ano kofanovo vol.

Determination of Cicarboxylic Acid Esters in Polylvinyl chloridel Film Extracts

Gig. Sanit., Vol. 36. No. 7, pp. 67-69 (1971): Myge Sanito (Eng. Transl. V. Vol. 36. No. 7-9.pp. 81-4 (1971)

84. Keller. A. A. Sheldon. A. w. and Simmons. I.

Fast Extraction Tests for Food-Grade (Poly(Vinyl Chloride))

Mod. Packag.. Vol. 48, No. 8. pp.42-4 (1975)

85. Keller. A.A.. Sheldon. A.W.. and Simmons. Icl.

Accelerated Extraction Tests for Food-Grade Uctyltin Stabilized PVC

Soc. Plast. Eng.. Tech. Pap.. Vol. 20.pp. 514-17 (1974)

86. Klermeler. F. Evers. K. - . and wibdbrett. G.

Use of Plastics for Foodse XIV. Simulated Practical Jest for Mikk pipes

Dtsch. Leoensm.-Rundsch.. Vob. 05, No. 13, pp. 305-11 (1909)

87. Kim. J.-W. and Iijima. T.

Oiffusion of Dye Mixtures in Nybon 6. Binary Mixtures of

Disperse Dyes

J. Appl. Polym. Sci.. Vol. 20,ppo 155-113(1976)5-11) (1569)

88. Klein. J.

Diffuston of Long Moleculies through Solid Polyethylene

I. Topologicai constraints 
J. Polym. Sci.e Polym. Phys. Secto. Vold 15. 2057-64 (2977)

89. Ktein. Je and Briscoe, B.je

olffustion of Long Molecules Through solid Polyethylene

11. Measurements and Resubts

3. Polym. Sci.. Polym. Physe Sect., Vol, 15. 2065-74 (1977)

90. Knibbe. D.E.

Theory of Extraction of Additives from Plastics by Swelling Solvents

Plastica, Vol, 24, No. 8, p. $358-63(1971)$

91. Koch, Jo, and Figge, Ko

Migration of Tin Stabillizers from PVC Hottles into Beer

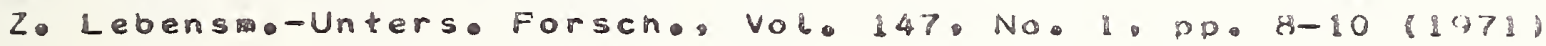

92. Koch, Jo. and Figge, K.

Decreasing the Fat Simulant Quantity in Migration Investigations on Plastics

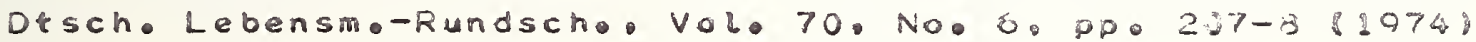

93. Koch. Jo and Fisge. K.

Alteration of the composition of fats by contact with plastics and its Effect on the Accuracy of the Total Migration Determination Methods

Dtsch. Lebenm.-Rundsch., Val. 71. No. 5. pp. 170-7 1975

94. Koch. Je. Robinson. L. and Figge. Ko

Determination of Fat Release by Foods. I. Methods

Fette. Seifen. Anstrichm., Vol. 78, No.9, pp. 371-7 (1976)

95. Komatswo Yo Namiki. Topand Mori, F.

On the Eutractability of Di-Alkyl Tin Compounds from Rigid Poly (vingl Chloride) Containers

Jo Food Hygo Soce Jpn. UShokuhin Eiseigaku Zasshib. Vol II. No. 1. pp.17-22(197)

96. Komarova. EoNo, and Maksimova. NoS.

Hygenic Properties of PVC/AES compositions

Plast. Massy. No. 12, pp. $29(1976)$ Intl. Polym Scio Technolo. Vol. 4, NO, S, PD. S (1977)

97. Kotova. VoN. Koval chuk, V.M. Platonova. T. V..

Tsivinskaya. Lok. and Elotsefon. E. S.

Toxicity Investigation of Polyformaldenyole plastics

Soviet Plastics, Vol. 1972. No. I. PD. 74-E IS72

98. Kovgan. N.A.

Hygientc Evaluation of Melalit Utensils for Food Products

vopre pitano. Vol, 28. No. 4. pp. 75-76 (1969)

99. Kwe i. Tok. and Zupko. HoN.

Diffusion in Glassy Polymers Io

J. Polyin. Sci. A., Vol. 2. No. 7. Dp. E67 (14itg)。

100. Kwei. T.K.

Difrusion in GLassy Polymers Vio

S. Polym. Sci. A.. Vol.z. No. I6. pp. 1849-1851 (1972) 
101. Kwei. T.k. and wang. Toto

Diffusion in Glassy Polymers

Polym. Sci. Technolo. Vole 6. Permeability plaste Films Coat. Gases. Vap. Liq. p p. $63-71$ (1574)

102. Kwei. Tok. Wang. T. T. and Zupko. H. M.

Diffusion in Glassy Polymers V. Combination of Fickian and Case 11 Nechanisms

Macrowol. Vol. 5.pp. 645 (1972)

1133. Lefaut. F.

Migration of Monowers in Foods

Ernaehrungsforschung. Vol. 16. No.4, pp.617-25 (1972)

$104 . L e h m a n n . H .0$.

Migration of Antistats in PLastics

Chem.. Phys. Chem. Anwendungstech. Grenzflaechenaktiven Stoffe. Rer. Int. Kongre. Vol. 6. No, I, po. E61-9 (137 I)

105. Leimgruber, KoA., and Figge. Ko

Substances Migraticn from Plastics Food Packaging to

contents as a Function of the Solvent volume to sample Surface Area

Soc. Plast, Enge NATEC. Nove $1977 . p p \cdot 4 j-43$

1J6. Lewis. ToJ.

Diffusion of Isopropyl Nitrate. Acetone, and Water into Nitrocellulose

Polymer. Vol. 19. pp. 285-290 (1978)

137. Machin. D. and Fogers. CoE.

Concentration Dependence of Diffusion Constants in polymers

CRC crit. Rev. Macromol. Sci., Vob. 1. ppo 245- Ij (1972)

138. Maksimova. NoSo, Sukhareva. Lov.. Guricheva, Z.G., Demidova.

V.k. Lazareva. N.P.. and sokolova, T.G.

Migration of Stabilizers from Polymers Used in Medicine

Plast. Massy. No. 10. pp. 61-z (1972)

19. Markelov. MaA.. and Semenenko. E.I.

Determination of Nicroconcentrations of Substances Miorating from

Polymer Materials to Nater

. Plast. Nasy. No. 1. pp.57-c (1576)

110. Matveeva. E.N.

Determination of the Migration of Antioxidant on the Surface of Polymer

Naterial

Plast. Massy. No. 8. pp. EE-G (1975)

11. Mazur. Ho. and Lewandowska. I.

Study of the Migration of denzophenone Derivative UV (Litht Stabilizers

Rocz. Panstwe Zakl. Hig., Vol. 27, No. S. pp. EII-19) (1976)

112. Meier. Lo

Results of Studies on the Migration of the Plasticizer from PVC into rhermoplastics 
Wastuerarbelter, Vol. 28. No.4. DP. IES-98 $(1577)$

113. Millen. we. and rawkes. S.

Diffuston of n-ALkanes in Polyldimetnylsiloxanesl

Macromolo. Vol. IC. NO. t. Fp.125\%-2 (1977)

114. Ministro per la Sanita. Il

Modification of the Regulation I5th April. 13k6. Health

Regulation for Nrapcings

Industria Conserve. Vol. 43. No.?. pp. 158-9) (1983)

115. Morano. Jo

Sorption of Vingl Chboride in Various polyfvinyt chloridel

Food simulating Solvent Systems

Pn. C. Thesis. Futgers Univ.. 1975

110. Morano J.R. Giacin. J.k. and Gilbert, S.G.

Sorption-Desorption of Vinyl Chloride in Selected PVC-Food Simultant Solvent systems

J. Food Sci.. VoL. 42. pp. 23081977 )

117. Morita. Z. Abul hossain. T.N.. and I isima. T.

Diffusion and Adsorption of a Model Cationic Dye.

N-Nitrobenzylamine. in Pclyacrybonitribe

Bull. Chem. Soc. Jpn. Vol. 48, No. 4, DP. 1196-9(1975)

118. Morsier. A. De

Migration of Plastic Adjuvant Agents whth hegard to Toxicological Aspects

Ernaehrungsforschung, Vole 16, No.4, pp. 537-4: (1972)

119. Narkis, N.. and Narkis. N.

Slow Felease of water-soluble Salts from Polymers

J. Appl. Polym. sci., Vol. 20. No. 12, po. J4Ji-c (1976)

120. Novitskaya. L.P. Kazarinova. Nof., and kuznetsova. VoN.

Determination of Certain Stabilizers-Antioxidants during Sanitary ond Chemical Studies of Polymeric Materials

Gig. Sanit.. No.7. pp. 74-7 (1977)

121. Ostromow, H.

Detection of Traces of Additives in Migration from Finished High Polymer Proaucts by vetermining the Functional Groups of Such Additives

Ann. Ist. Super. Sanita., Vol, 8, No.2, Fp. 474-89)(:972)

122. Pestova. A.G.. Davidan. R.G., and Vhadimiskaya. F. E.

Toxiclty Characterization of Polymeric Materials Used in

the food Industry

Soviet PLastics. Vol. 1972. No.3.PP. 84-6 (I972)

123. Peterlin. A.

Dependence of Diffusive Transport on Morphology of Crystalline Polyineri s. Macromol. Sci. E. Vol. 11. No.1.pp.57-977(1975)

124. Petrova. L.I.

Migration of Low-Nolecular-weight substances

from Polystyrene Plastics into Liquid Media 


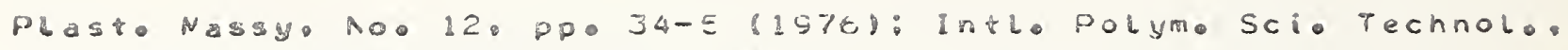
Vol. L. NO. S. PP. $72 \varangle 19771$

125. Petrova. Lolo, and Eoikova. Z.k.

Study of the Health Aspects of JPM-703 Holo Dolystyrene

Plaste Massy. No. 5, pp. 62 (1976): Intl. Polym. Sci. Technol. Vol. 4. No. 1.pp. 24 (1577)

126. Petrova. L.I.. and Eoikova. Z.K.

Possibility of the Use of $A B S$ Plastics in contact with Food

Plast. Massy. No. 12. PD. 31 (1976) Intlo Polym. Sci. Technolo. VOL. 4. NO. 5. Pp. S9 (1977)

127. Petrova. L.I. Boikova. Z.K.. and Guricheva. Z.Go

Migration of Styrene from Polystyrene Plastics into Food products and a Method for Determining the Monomer in them

Plast. Massy. No. II. Pp. 57-60 (1970)

128. Petrova, LoI., Guricheva. Z, Go. Bablova. GoDo. Egorovas EoI. Maksisova. NeS。: and Rudakova, M.N.

Toxicity Properties of High Impact Pobystyrenes Based on Various Rubbers

Soviet Plastics. No. 5. pp. 67-G(1972)

129. Pfab. Wo

Methods for Determining rotal Migration into Fatty Foods

Ann. Ist. Super. Sanita. Vol. 8, No.2, po. 385-94 (1972)

230. pqab, Wo

Diffusion in a Plastic-Fat System

otsch. Lebensmo-Rundsch., Vol, 69, No.4. pp. 151-62 (1973)

131. Pfab. Wo. and Muecke: Go

Mloration of Selected Monomers in Foods and Food Simulants

Dtsch. Lebensm--Rundsch. Vch.73, No.1.pp.1-5 (1977)

132. Plater. ro. and Figge.k.

Migration of Additives of Plastic Manufacturing from Films into

Cils and Fats, and Model Systems. Comparison of Gravimetricaliv Determineo Residues from Extraction Solvents with Actual

Extracted Additives

Dtsch. Lebensm.-Rundsch. Vcl. 67. No. 8. pp. 265-9 (1971)

133. plekacz.r.

Public Health Evaluation of Polyethylene Terephthalate

Rocz. Panste Zakl. Hige. Vol. 25. No. 3. pp. 281-285(1974)

134. Pliner, S.kh.. and Govorukhina. V.I.

Diffusion Properties of Plastics films in Brine

Ryon. Khoz.. Vol. 45. No. 1, pp. 70-71 (1969)

235. Poorten. R. Van Cer

Migration from Plastics Packaging Materials into Dairy Products

Revie De L.Agriculture. Vol. 27 . No. 6. pp. $1511-1520(1974)$

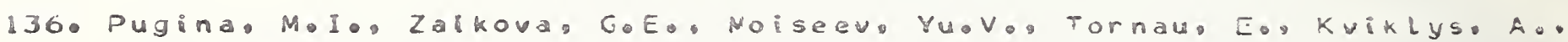
Daumantiene, Vo, Jaskelevicius. B.. and Maciulis. L.

Effect of Stabilizers and Stabilization Methods on the properties 
of Polymer Materbalso 7. Kbnetic Laws of Diffusion

Stablllzotion of rolyamides

Llet. Tsr Mokslu Akad. Darb. Ser. G. No. 2. pp. 69-74 (1974)

137. Quankenbos. H.M.

Plasticizers of Vinyl Chloride Resins Migration of plasticizer

Ind. Eng. Chem. Vol. 4E, pp. 1335 (1954)

138. Reed. N.C.. Klemm. F.F. and Schulz. E。F。

Plasticizers of Vinyl Chlorice fiesins. Removal by Cib. Soapy water and Dry Powders

Inde Enge Cheme. Vol. 46. pp. 1344(1954)

139. Rhee. C.K., and Ferry. J.C.

Diffusion of Fadioactively Tagged Penetrants through Random and Block styrene-eutadiene Copolymers and Filbed cis-polybutadiene

J. Appl. Polym. Sci.. Vol. 2l.pp.467-476(1977)

140. Rhee. Cok. and Ferry. Joc.

Diffusion of Fadiodctively Tagged penetrants throunh Rubbery polymerso I. Penetrants with very Low Solubility

J. Appl. Polym. Sci.. Vol. 21. ppo773-781(1377)

141. Rhee. C.-K.. Ferry. J.D.o and Fetters. LoJ.

Diffusion of Radioactively Tagged Penetrants through Rubbery Polymers. II. Dependence on Molecular Length of penetrant

J.Appl. POlym. Sci.. Vol.21, No.3, pp. 783-9.31977)

142. Rienzi. Ro

Determination of Nigration of Vinyl Chloride Monomer out of PVC Containers for Beverages

Ind. Celle Bevande. Vol. 4. No. 5. pp. $110-118$ (1975)

143. Robinson. Lo

Anal. Sys. for the Admission of New Additives and the Control of Nigration

Ann. Ist. Super. Sanita.. Vol. E. No.2. Fop.542-9 (1972)

144. Rozaci. Co. Burda. Jo. Hlavnicka. J.e Krizek. V.o. and Suoboda. D. Migration og Additives from Kubber

Plast. Kauck. Vol. 11. No. 12. pp. 360 19748

145. ROE. R. J.

Physical Factors Controlling fetention of Additives in Polyolefins

ACS. Div. Crge Codt. Plast. Chem.. Prept.. Vol. 34. No. 2. pp. 132-7 $(1974)$

146. Ronleder. K. and Bruchnausen. R. Von

Direct Determination of Plasticizer Migration from plastics into Fat and Fat-Containing Foods

Dtsch. Lebensm.-Fundsch., Vol. 68. No.6. pp. 180-184(1972)

147. Rombusch. Ko. and Mahs. Go

On the Distribution and Nigration of Antistatic Agents in specimens kath from Polyolefins and Polystyrene

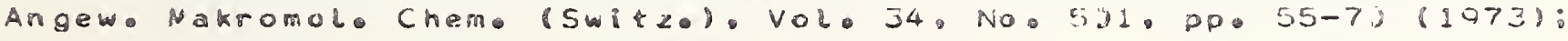
NASA-TT-F-14754 
148. ROSt, toE.

Contawination of fats with Phthalates from Plastics

fette. Seifen. Anstrichmo. Vol. 72 . No.7. po. 552-3 (1974)

149. Rubin. R.d.

Biomedical Implications of the Migration of Phthalate Ester Plasticizers from PVC Plastic

Tech. Pap. Rego Tech. Conf.. Soc. Plast.. Eng. Palisades Sect. Pp. $81-3$ (March 20-22, 1973)

150. Rudt. U.

Effect of Plastics on Foods

Gordian. Vol. 71. No.4. pp. 1.32-15: No.5. po.141-45(1971)

151. Rysavy. C.

water Extraction of Stabilizing additives and its Effect on

Atwospheric Aging of Pclypropylene Films

Plasty KawC. Vol. 13. No. 10. DP. 297-9 (1976)

152. Sal ame. N.

The Prediction of Liquid Permeation in Polyethylene and felated Polymers

SPE Trans. Vol. 1. No.4.ND. 1-11 (1961)

153. Salame. Mo. and Pinsky. Jo

permeability Prediction

Mod. Package. No.

$81962)$

154. Saluatore. Ge

Method of Determination of the Global Migration of PLastics and fubbrin in Fatty foods.

Rass. Chim.. Vol. 27. No. 2, pp. 57-69(1975)

155. Seidber. Ho. Haertig. M. Wogzon. Ho. and Jhde. NoJo

Examinations on the Migration of (1-14C)-2-Ethyl-Hexyl Ester of

Di-N-Cctyl Tin Dithioglycolic Acid (Stabilizer ots is) from rard

PVC into Edible Cil

Nahrung. Vol. 15. No. 2. pp. 1E7-90 (1971)

156. Setaler. H.. Woggon. H.. Haertig. M.. and Uhde. WoJ.

resting of Plastic Commodities: the Migration of

His(z-Ethylhexyl) (CDi(Cctyl-1-14C) Stannylene)Dithio) Diacetate

from Rigid Polvivingl Chloridel into Edible lil

Nahrung. Vol. 13. No. 3. pp. 257-64 (1909)

157. Seidler. Ho. Woggon. Ho. and Haertig. Mo

Testing Plasticso Study of the Nigration of Di-n-Dctyl (1-(14)C) Tin 2-Ethylhexyl-Dithioglycolate from Rigid Poly(vinyi chloridel int Eoible cils

Nahrung. vol. 13. No. 3. pp. 157-64 (1909)

158. Semenenko. E.I.. and Markelov. M.A.

Physicochemical easis of Sanitary Chemistry of Polymer Materials

Khime Farm. Zh. Vol. 10. No. G. ppo 129-13E (1575)

Pharw. Cheme Jo (Engl. Translo). 
Preliminary Hysienic Evaluation of Silicones intended for contact with Foods

Hocz. Panst. Zakl. Higo. Vol. 21. No.2, Do. 169-75 1972)

160. Sokolowskag R.

Phenol Cetermination Methods and their Aoplication to Hygienic

Evaluation of Dlastics utility Products. IV. Mig ation of phenshs

from Products Made from phenol-Formaldehyde and Epoxy-Phenol fiesins

Rocz. Panst. Zakl. Hig. Vol. 2u. No.4. pp. Zez-8.91969)

161. Sokolowska. R.

Identification of Antioxidants lsed in Polyethybeneo II Identification in Plastics Items and Nigration Study

Rocz. Panst. Zakl. Hig., Vol.2S. No.6. pp.tel-72 19698

102. Svoboca. P.. Kralicek. J.. Vondruskova. E. Rozaci. O. Vanek. Po. and Dockal. Jo

Migration of Paraffin waxes. D. Benavior of Parafin $59 / 6$ in

SEF and in Natural Fubber

Plast. Kaucuk. Vol. 13. No. 8. pp. 24141970s

163. Tarasova. N.A.. Feofanov. V.C.. and Gul V. E.

Benzene Content in Medium-Pressure Polyethylene

Gig. Sanit.. Vol. 36. No. 11. pp. 184-16 (1971)

104. Troparevsky. A. Pisarello De Tro. Molo. and Mitta. A.E.A.

Determination of Migration of Plasticizer by 14 C Labeded Compounds

Report CNEA. No. 391. ppo 11. Avail. INIS Atomindex. Vol. 7. No. 5. Abstr. $227 C$ (1S7E)

165. Tsam. Z. M.

Hygenic Evaluation of New Polymer Materials Used in Drinking water System

Hyg. Sanit. Vel. 36. No.7-S. pp. 453-5 (1971)

166. Unde. w.j., and hoggon. H.

Testing Plastics. 3. Migration Fate of Hydroxyphenylbenzotrizzole

Plastics into Edible Cil

Nahrung. Vol. 12. No. E. pp. 825-34 (ISt8)

167. Unde, No. and wosgan. H.

Analysis of Plastics Utensils. Migration of Antioxidants from food wraplings

Dtsch. Lebensm.-Fundsch. Vol. 67. No. 9. pp. 237-262 69718

168. Unde, w. J. and woggon. H.

Recent Results Concerning the Migration Behavior of Benzophenone eased Ultraviolet Absorbents from Polyolefins in Foods

Nahrung. Vol. 20. No. 2. pp. 185-34 (157t)

169. Unde. Wol. Woggon. Ho. and Koenler. U.

Testing from plasticse zo Migration of 4. 4 -Thio-bist6-t-futyt-m-Crisoly Plastics into Edible Dil

Nahrung. Vol. 12. No. E. pp. $91 \equiv-\angle 4(1968)$

170. Unde. WoJ., Woggon. H. 2ydek. G. and koehler. U.

Testing Plastics. Nigration of Uv-Absorbents from food Packaying Materials 
Dtsch. Lebensm.-Fundsch. Vol. Es. No. S. pp. 271-78 (1965)

171. Varsano. J.L. and Gilbert. S.G.

Evaluation of Interactions Petween Polymers and Low-Molecular Neight Compounds by GLC (Gas-Liquid Chromatography). I. Methodology and Interact Evaluation

J.Pharm. Sci.. Vol. E2. No. 1.pp. 87-91 (1973)

172. Vieth. W.F.o ano Amini. Mary A.

Generalized Dual Sorption Theory

Polym. Sci. Technob. 6, Permeability Plast. Films Coat. Gases, Vapo. Liqe, pp. 4E-61 (1974)

173. Vieth. W.R., Howell. J.M. and Hisien. J.H.

Dual sorption ineory

3. Membrane Sci. Vol. 1. pp. 17 (197)

174. Voroboev, VoP. Gurlcheva. Z.G. Petrova. LoI.. and Sazhin. B.I.

Oescription of the Nigration cf Low-Molecular-weight Components from Polystyrene Plastics by viffusion Equations

Plast. Nassy. No. 7. pp. 57-60 (197z)

175. Wang. T.T. and Kwei. T.K.

Difrusicn in Polymers

Permeability of Flastic Films and coatings to Gases, Vapors. and Liquids. Hopfenberg. h.B. Ed.

Plenum Press. N.Y. PD. EZ (1974)

176. Westerohl. C.A.L.

Diffusion and Persistence of Silicone oil in Rubbers and Low Oensity Polyethylene

Picatinny Arsenal Technical Report. No. 2185. March 1976

177. Westlake. Jofo, and Johnson. Mo

Diffusion of Stabilizers in Polymers. I. 2. 4-Dihydrox vbenzophenone in Polyolefins

1. Appl. Polym. Sci.. Vol. 19. No.2. pp. 319-34 (1975)

178. wewerka. Do. Fruwirth. Co, and rummel. K.

Reactions in Crosslinked Polymers. z̈. Puritication of

Polytutadiene by Extraction with Liquefied Butane

kaut. Gummi. Kunstst., Vol. 27. No.3.pp.93-3(1974)

179. Wharton. FoD.. Jro. and Levinskas. GoJ.

Toxicological studies on Nitrile Earrier Polymers

(hem. Ind. (London). Vol. 11.pp.47-4 (1976)

180. Wieczorek. Ho

Isolation and Guantitative cetermination of organotin compounds in Edible oll and Vinegar after contact with stabilized Figid PVC Films

Otsch. Lebensm.-Fundsch.. Vol. 66, No. 3, pp. 92-95 (1975)

281. Willobrett. G.

The Extracting Effect of vetergent Solutions on pVC Milk Tubes

Milchwissenschaft. Vol. 28. No.7. pp. 443-446 (1773)

182. Wildorett. G. 
Oiffusion of Phthalic Dcid Esters from PVC Milk Tubing

Environ. Health Perspect. Vol. 3. pp. 23-35 11973 )

183. Wobrett. G. Evers. K. H. and Kiermeier. F.

Investigations and Observations on the Application of plastics

for Foods. XII. Migration of Monomeric Plasticizers from PVC Milk

Tubes into Cleaning Solutions

Fette. Seifen. Anstrichm.. Vol. 71. No. 4. ppo $33 j-335$ (1909)

184. Wildbrett. G. Evers. K.-W. and Kiermeier. F.

Investigations and observations on the Application of plastics for Foods. XIII. Interaction of PLastics with Milk

Z. Lebensm.-Unters. Forsch. Vol. 142. No. 3. po. 205-15 (1974)

18b. Wildbrett. G.. Evers.k. K.. and kiermeier. F.

Investigations and Observations on the Application of plastics

for Foods. XVI. Diffusion Process in PVC Tuing for Foods

Werkst. Kerros.. Vol. 22. No.9. pp. 753-759 (1S71)

186. Wilks.R.A.. Jr.. and Gilbert. S.G.

Sensory and Instrumental Evaluation in Mudel Systems of Fesidues

Migrating from Can Coatings

J. Food Sci.. Vol. 37. No. 1. pp.72-76 (1972)

187. Woggon. Ho. Jehle. D.. and Uhde, Woj.

Testing of Plastic Commoditieso Migration of PVC lPolylvinyt

Chloridell Stabilizers into Edible Cil

Nahrung. vol. 13. No.4. pp. 343-50 (1969)

188. Woggon. H. and koenter. U.

Testing of Plastic Utensils Polarographic Determination of Di-l?-EthylHexyl)-Phthalate and Investigation of the Tendency to Migration

Kunststoffe, vol. 57, No. 7. pp. 583-586 (19B7). NASA-TT-F-13HPA

189. Woggon. Hi. and koenler. U.

Testing Plastics. 4. Migration of Plasticizerifrom

Polymethacrylates into Food

Ernaehrungsforschung. Vol. 13. No.4. pp. E51-55 (1963)

190. Woggon. He. Koehler. U.. and Uhde. Wo-j.

Testing Plastics. Migration of Cadmium Pagments from Food Packaging Materlals

Dtsch. Lebensm.-Rundsch.. Vol. 64. No. 8.pp. 243-47 (1968)

191. Woggon. He. and unde. W.J.

Antistatic Finishing of Plastics from the Food-Toxicological Point of View

Nahrung. Vol. 21. No. 3. pp. 235-45 (1977)

192. Woggon, ho. Unde. Wo Jo. and Saeuberlich. H.

New Results on the Migration of Organotin stabilizers in Foot

Ernaehrungsforsehung. Vol. 16. No.4. pD. E45-55 (257?)

193. Woggon. H., Unde, H.J.. and Zydek. G.

Testing of Plastics. Migration of 2.6-Oi-tert-Bwtyl-p-Cresol iblTi in Edible oils

7. Lebensm-Unters. Forsch., Vol. 138. No. z. 2p. 169-77(1958) 
194. Yen. w.C.r.

Qwantitative and cullidative Study of the kigration of Oryanotin stabiblzer from polyivinyl chloridel to liquid fonds

Oiss. Abstr. Int. E. Sci. Enge. Vol. 31. No. 3. pp. 1343: Order. No. $73-1 E S E Z(1976)$

EUF: 1627

$3:$

NO CORRECTICAS AFPLIED.

DUFESEND 
REVIEW AND EVALUATION OF AVAILABLE MIGRATION MODELS

\section{Introduction}

Migration of minor constituents from a polymeric film to a food or simulating solvent is controlied by both transport and thermodynamic factors. Neither can be ignored if a complete description of migration is desired. For example, the diffusion of a species (hereafter referred to as the "migrant") from a polymer film of thickness 2 e and volume V to a stirred solvent of volume $v_{s}$ is given by

$$
\frac{M_{t}}{M_{\infty}}=1-\sum_{n=1}^{\infty} \frac{2 \alpha(1+\alpha)}{1+\alpha+\alpha^{2} q_{n}^{2}} \exp \left(-D q_{n}^{2} t / \ell^{2}\right)
$$

where the $q_{n}$ 's are the non-zero positive roots of

$$
\tan q_{n}+\alpha q_{n}=0
$$

and

$$
\alpha=\left(V_{s} / V_{p}\right){ }^{k}
$$

$D=$ migrant diffusion constant in polymer

$K=C_{s} / C_{p i}=$ equilibrium distribution coefficient

$c_{p}=$ equilibrium concentration of migrant in film

$C_{S}=$ equilibrium concentration of migrant in solvent

$M_{t}=$ amount of migrant transfered to solvent at time $t$

$M_{\infty}=$ amount of migrant transfered to solvent at infinite time

If the initial concentration of migrant in the polymer film was $C_{0}$, then $M_{0}=V_{p} C_{0}$ and

$$
1-\frac{r_{p}}{C_{0}}=\frac{M_{\infty}}{M_{0}}=\frac{\alpha}{\begin{array}{c}
1+\alpha \\
-33-
\end{array}}
$$


Notice that Eq. (1) is a function of both $D$ (a transport property) and $K$ (a thermodynamic property). Equation (4) detemins the maximum amount of migration that can occur and is strictly an equilibrium or themodynamic property of the system.

Equation (1) is the complete solution for a certain class of migration problems; viz., those systems which obey Fick's two laws of diffusion and for which $D$ and $K$ are known. Therefore, modeling migration behavior for this type of system can be reduced to estimating, either theoretically or by semi-emperical methods, $K$ and $D$.

If the polymer film is appreciably penetrated by solvent, the diffusion constant is not constant and Eq. (1) will no longer hoid. But even in these systems Eq. (4), which is only a function of $K$, is valuable in the sense that it yields an upper limit for migration. Of course, this upper limit equals $M_{0}$ (complete extraction of the migrant) if the solvent mass is much larger than the film mass; i.e., if the film is placed in an infinite solvent reservoir, migration continues to completion at infinite time. However, in many food packaging applications (e.g. plastic bottles) $\alpha$ will be finite and a residual amount of migrant will be retained by the film.

In the next section, methods of theoretically estimating distribution coefficients will be discussed which will then be followed by a discussion of theoretical methods for estimating diffusion constants. A general and practical migration model will ultimately depend on how well $\mathrm{K}$ and $\mathrm{D}$ (and their temperature dependences) can be calculated from the physical properties of the polymer, solvent, and migrant.

\section{Distribution Coefficients}

In principle, a relatively good estimate of $K$ should be possible for some polymer/solvent/migrant systems by using either the Flory equation of state theory of solutions ${ }^{2-4}$ or the lattice fluid (LF) theory of Sanchez and Lacombe ${ }^{5}$. An important prerequisite for the application 
of either theory is that the thermodynamic behavior of the migrant + polymer can be treated as an equilibrium mixture of two fluids. The amorphous component of a semi-crystalline polymer, such as polyethylene, can be treated as an equilibrium liquid if the temperature is above the polymer glass transition temperature. Under these conditions, the chemical potential of any organic migrant species (liquid or gas) within the amorphous regions can be calculated.

According to the well-known Flory-Huggins (F-H) theory of solutions ${ }^{6}$, the chemical potential of component 1 in a binary mixture is given by

$$
\left(\mu_{1}-\mu_{1}{ }^{0}\right) / R T=\ln \phi_{1}+\left(7-V_{1} / V_{2}\right) \phi_{2}+x \phi_{2}^{2}
$$

where $\mu_{1}{ }^{0}$ is the molar Gibbs free energy of pure liquid component 1 at temperature $T, \phi_{1}=1-\phi_{2}$ is the volume fraction of component $1, V_{1}$ and $V_{2}$ are the respective molar volumes of the two components and $x$ is the reduced residual chemical potential ${ }^{4}$. In the original formulation of F-H theory, $x$ was strictly an energetic parameter that was proportional to the energy required to form a 1-2 bond from a $1-1$ and $2-2$ bond. It also had a simple $1 / T$ temperature dependence and was independent of solution composition. Now it is known that $x$ is in general concentration dependent and possesses a more complicated temperature dependence than 1/T. Experimental7y, $x$ is treated as an empirical parameter which is adjusted as a function of concentration and temperature to fit experimentally determined chemical potentials. 
Even in solutions containing polar components, positive $x$ values are usualiy required ${ }^{4}$. Large positive $x^{\prime} s$ are, of course, thermodynamicaliy unfavorable and will limit miscibility.

This positive character of $x$ has highlighted the failure of F-H theory because the sign of $x$ should be the same as that of the heat of mixing, $\Delta H_{m}$. Exothermic mixing requires a negative $x$, yet there exist many examples where $\Delta H_{m}$ is negative and positive $x^{\prime} s$ are required for the chemical potentials. Even more puzziling within the context of F-H theory is that large negative heats of mixing often occur with mixtures of non-poiar components which require relatively large positive $x$ values (see Table I for some examples). However, both the new Flory and LF theories have resolved this apparent paradox. Experimentally, $x$ often has a large positive entropic component which arises, according to the Flory and LF theories, from differences in the equation of state properties of the pure components. Formaliy, the concentration dependence of $x$ can be expressed as

$$
x=x_{1}+x_{2} \phi_{2}+x_{3} \phi_{2}^{2}+\cdots
$$

There are two important limiting values of $x$ :

$$
\begin{aligned}
& x_{j}=x\left(\phi_{1}=1\right) \\
& x^{\infty}=x\left(\phi_{7}=0\right)=\sum_{1}^{\infty} x_{i}
\end{aligned}
$$

In almost all polymer solutions that have been studied, $x^{\infty}>x_{p}$ for the solvent chemical potential. 
At equilibrium, the chemical potential (or activity) of the migrant $\mu_{p}$ in the amorphous regions of a semi-crystalline polymer will equal the chemical potential $\mu_{s}$ of the migrant in the solvent phase:

$$
\mu_{p}=\mu_{s}
$$

Let the migrant be component 1 and present in small quantities compared to the polymer film or simulating solvent; thus $\phi_{2} \rightarrow 1$ and the migrant chemical potentials approach the following limiting forms:

$$
\begin{aligned}
& \left(\mu_{p}-\mu^{0}\right) / R T=\ln \phi_{p}+1+x_{p}^{\infty} \\
& \left(\mu_{s}-\mu^{0}\right) / R T=\ln \phi_{s}+\left(1-V_{m} / v_{s}\right)+x_{s}^{\infty}
\end{aligned}
$$

where $V_{m}$ and $V_{S}$ are the molar volumes of migrant and soivent respectively $\left(V_{m} / V_{p} \simeq 0\right.$ and is ignored), $\phi_{s}$ is the migrant volume fraction in the solvent phase, $\phi_{p}$ is the migrant volume fraction in the polymer phase and $x_{p}^{\infty}$ and $x_{s}^{\infty}$ are the $x^{\infty}$ values of the migrant in polymer and solvent phases, respectively. At equilibrium, Eq. (9) holds and thus the distribution coefficient is given by

$$
K=\phi_{s} / \phi_{p}=\exp \left(V_{m} / V_{s}+x_{p}^{\infty}-x_{s}^{\infty}\right)
$$

Equation (12) offers an alternative to extraction experiments for experimentally determining distribution coefficients. Recent advances in gas chromatographic techniques have made it possible to determine $x^{\infty}$ in low molecular weight systems such as $n$-hexane/squalene ${ }^{7}$ and in polymer/solvent systems such as polyethylene/n-decane ${ }^{8}$. The necessary equations required to obtain chemical potentials from equilibrium chromatograms are discussed in references 7 and 8 
and in more recent papers by Purne $11^{9}$ and Bonner and Brookmejer 10 :

For polymers, measurements are normally carried out above the polymer melting point or glass transition temperature. These temperatures will usually be well above the anticipated use temperatures of the polymeric food packaging material. However, with the aid of theory, experimental $x^{\infty}$ values can be extrapolated accurately to lower temperatures.

The Flory ${ }^{2-4}$ and lattice fluid ${ }^{5}$ (LF) theories incorporate the "equation of state" properties of the pure component fluids. Both theories require 3 equation of state parameters for each pure component which are determined from PVT data. For the LF, about 60 low molecular weight fluids ${ }^{5}$ and 10 different polymers ${ }^{11}$ have already been so characterized. For a binary mixture, LF theory requires 7 parameters: 3 for each pure component, which are already known or are calculable from PVT data, and a seventh parameter that characterizes the interaction between the two components. The Fiory theory requires an eighth parameter that is related to the surface/volume properties of the pure components. A relatively concise review and comparison of these two theories has been given by Sanchez ${ }^{12}$.

$$
\begin{aligned}
& \text { For the LF, } x^{\infty} \text { for component 1, the migrant, is given by } \\
& x^{\infty}=\frac{M_{1}}{v_{1}^{*} \rho_{1}} \tilde{\rho}_{2} x_{1}+\left(\tilde{\rho}_{1}-\tilde{\rho}_{2}\right) / \tilde{T}_{1}+\left(\tilde{v}_{2}-1\right) \ln \left(1-\tilde{\rho}_{2}\right)-\left(\tilde{v}_{1}-1\right) \ln \left(1-\tilde{\rho}_{1}\right) \\
& +\ln \left(\tilde{\rho}_{2} / \tilde{\rho}_{1}\right)
\end{aligned}
$$

$$
\begin{aligned}
M_{1}= & \text { molecular weight of component } 1 \text { (migrant) } \\
T_{1}^{*}, v_{1}^{*}, \rho_{1}^{*}= & \text { characteristic temperature, volume, and mass } \\
& \text { density, respectively, of the migrant }
\end{aligned}
$$




$$
\begin{gathered}
\hat{p}_{1}=p_{1} / \rho_{1}^{*}=1 / \tilde{v}_{1} \quad \text { reduced migrant density } \\
\tilde{p}_{2}=p_{2} / \rho_{2}^{*}=1 / \tilde{v}_{2} \begin{aligned}
\text { reduced polymer density or reduced } \\
\text { simulating solvent density }
\end{aligned} \\
\tilde{T}_{1}=T / T_{1}^{*} \quad \text { reduced migrant temperature } \\
x_{1}=\Delta P^{*} V_{1}^{*} / R T
\end{gathered}
$$

and $\Delta P^{*}$ represents the net change in cohesive energy density upon mixing components 1 and 2 at the absolute zero of temperature. $x_{1}$ is the only unknown parameter in Eq. (13). All others are known or derivable from pure component PVT data. An experimental value of $x^{\infty}$ would establish the value of $x_{\eta}$, of course, but other kinds of solution data (often more accessible experimentally) such as heats of mixing, critical temperatures, solution densities, etc. can be used to determine $X_{1}$. Thus, LF theory offers a method of calculating $x^{\infty}$ values without actually measuring chemical potentials directly. To illustrate this possibility, $x^{\infty}$ values have been calculated for some polyisobutylene solutions using $\Delta H_{m}$ data to fix $X_{1}$. As a polymer solution becomes dilute in polymer (component 2), the heat of mixing approaches a limiting value, $\Delta H_{m}(\infty)$, defined by:

$$
\Delta H_{m}(\infty)=\lim _{\phi_{2} \rightarrow 0} \Delta H_{m} / \phi_{2}
$$

In Table I $\Delta H_{m}(\infty)$ values at $298 \mathrm{~K}$ for polyisobutylene in n-pentane, n-octane, cyclohexane, and benzene are tabulated. A striking feature of the data is that 3 out of 4 of these non-polar solutions are exothermic. Notice, however, that all 
of the calculated $\Delta P^{*}$ and $X_{j}$ values are positive as one might expect for these non-polar components. The calculated $x_{1}$ values have then been used in Eq. (13) to calculate $x^{\infty}$; the experimental $x^{\infty}$ values are also tabulated in Table I for comparison. 47 so listed are the experimental and theoretical values of $x_{j} \equiv x(\phi=1)$ which shows how $x$ can vary with concentration. Although the agreement is not spectacular, it is encouraging. Similar results can be obtained with the flory theory whereas the Flory-Huggins theory would fait miserabiy. 


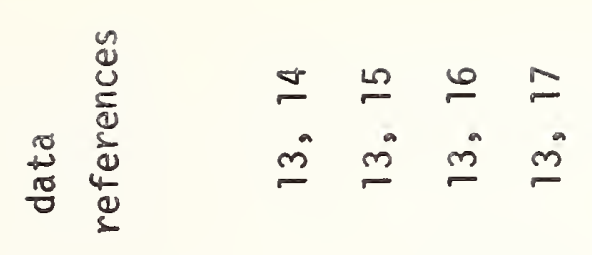

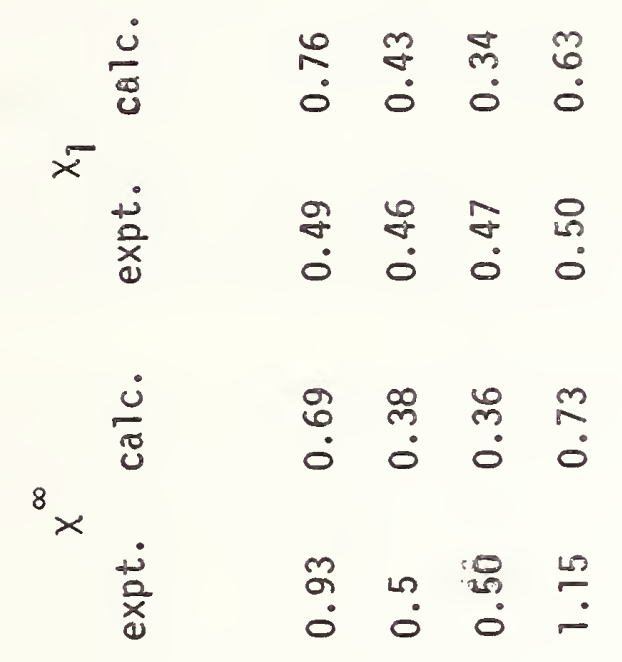

岕|

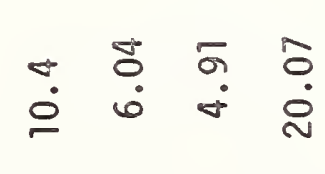

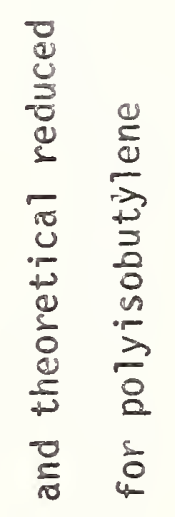

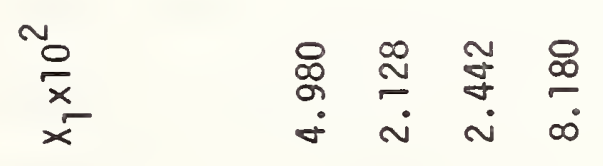

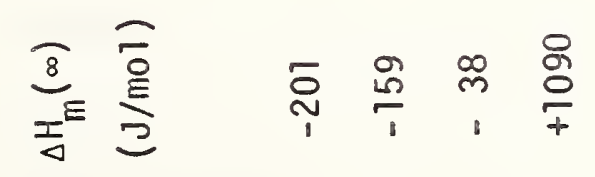

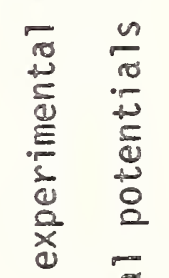

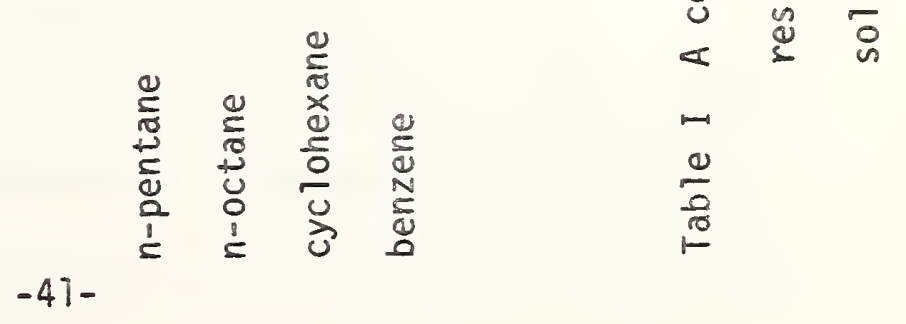


Diffusion Constants

\section{General Properties}

Typically, the self-diffusion constant $D$ of an organic liquid is about $10^{-9} \mathrm{~m}^{2} / \mathrm{sec}$. At low concentrations in a polymer, the same organic species diffuses at a drastically reduced rate; $D$ can vary from about $10^{-13} \mathrm{~m}^{2} / \mathrm{sec}$ at $\mathrm{T}_{\mathrm{g}}+100 \mathrm{~K}$ to about $10^{-20} \mathrm{~m}^{2} / \mathrm{sec}$ near $\mathrm{T}_{\mathrm{g}}$.

Most diffusion studies have taken the form of permeation or sorption experiments performed on amorphous polymers (lightly crosslinked) above their glass transition temperatures. Whereas diffusion behavior is relatively simple at temperatures above $T_{g}$, it is exceedingly complex at temperatures near or below $\mathrm{T}_{\mathrm{g}}$.

In the usual absorption experiment a polymer film, initially free of diffusant molecules, is suddenly exposed to an organic vapor at a fixed pressure and the gain in weight of the film is monitored as a function of time. Desorption of the diffusant can also be studied by reducing the pressure to a new fixed value and following the film weight loss.

Data from a sorption experiment (either absorption or desorption) are generally represented by plotting the amount of vapor $M_{t}$ absorbed or desorbed against the square root of time. At long times equilibrium is approached and $M_{t} \rightarrow M_{\infty}$.

$$
\text { Crank }^{1} \text { discusses at length the method of data }
$$
analysis required to obtain diffusion constants from sorption data. It is assumed that $D(c)$ is a function of concentration $c$, but not of time, and that the diffusant concentrations at 
the firm surface increase or decrease instantaneously with pressure to their equilibrium values. Under these conditions the sorption is called Fickian and sorption curves are expected to possess the following properties:

a) Sorption curves are initially linear in $t^{1 / 2}$. For absorption, the linear region extends to over $60 \%$ of $M_{\infty}$. For desorption, linearity is obtained almost up to equilibrium if, as would normally be expected, $d D / d c>0$.

b) Above the linear portions, both absorption and desorption are concave to the $t^{1 / 2}$ axis, irrespective of the form of $D(c)$.

c) Sorption curves are superimposable. A series of absorption curves for films of different thicknesses ( $(l)$ are superposable if $M_{t}$ is plotted against $t^{1 / 2} / \ell$. The same applies to a corresponding series of desorption curves.

These properties are independent of the form of $D(c)$ and provide an experimental means of determining whether a given system exhibits Fickian sorption. One of the most important findings of sorption studies is that at temperatures we 11 above $T_{g}$, the sorption kinetics of organic vapors are invariably Fickian. Temperature dependent sorption studies have also revealed another characteristic property of small molecule diffusion in polymers: the temperature dependence is strong and non-Arrhenius. A plot of $\log D$ vs $1 / T$ will usually be non-linear. For example, Hayes and Park ${ }^{18}$ studied sorption of benzene in naturai rubber and found that the apparent activation energy, $\Delta E^{*} \equiv-R \mathrm{~d} \ln \mathrm{D} / \mathrm{d}(\mathrm{T} / \mathrm{T})$, is about $29 \mathrm{~kJ} / \mathrm{mole}$ at $373 \mathrm{~K}$ but increases to $96 \mathrm{~kJ} / \mathrm{mol}$ at $273 \mathrm{~K}$. 
Another feature of the temperature dependence, which is

especially relevant for migration studies, is the finding that

$\Delta E^{*}$ often appears to be independent of the diffusant's chain length or

branching. Such has been the case for isomeric hydrocarbons

in natural rubber ${ }^{19}$ and polyisobutylene 20 and $n$-alkyl acetates

in polymethyl acrylate 21,22 . In the case of natural rubber,

the constancy of $\Delta E^{*}$ has been shown to hold up to as

large a molecule as octadecane ${ }^{23}$. These findings tend to

support the thesis that the temperature dependence of

diffusion is largely determined by the properties of the

poiymer and is relatively independent of the size and shape

of the diffusant.

2. Diffusion above $T_{g}$

Theories of the diffusion constant fall into two broad classes: In one, which is especially relevant for migration studies, attention is directed at how the magnitude of $D$ and its temperature dependence are affected by such factors as the size and shape of the diffusant, the nature of the polymer, and the intermolecular interaction between diffusant and polymer. In the second class, interest is focused on interpreting the concentration and temperature dependence of $D$ and not its magnitude. A 1973 review of the latter class of theories is available 24 while the former and more important class was reviewed in 1968 by Kumins and Kwei 25 .

of the theories reviewed in 1968, two stand out. These are the free volume theories of Cohen and Turnbu 1726,27 and Bueche 28 . Both theories require the probability $P\left(v^{*}\right)$ that the local volume $v$ associated with the molecule or a "segment" of the molecule be greater than some critical volume $v^{*}$. The theories are different in that different 
methods are used for calculating $P\left(v^{*}\right)$. Conen and Turnbull assumed that a multinomial distribution of free volumes exist in a liquid to derive:

$$
\begin{aligned}
& P\left(v^{\star}\right)=\exp \left(\gamma v^{\star} / v_{0} f\right) \\
& D \sim \bar{u} P\left(v^{*}\right)
\end{aligned}
$$

where $f$ is the fractional free volume, $v_{0}$ is the molecular or segment volume when $f=0, \gamma$ is a dimensionless constant $(1 / 2<\gamma<i)$, and $\bar{u}$ is the average molecular or segment velocity $\left[\bar{u}=(k T / M)^{1 / 2}\right]$. Beuche used the thermodynamic theory of fluctuations, orginally derived by Einstein, to obtain

$$
\begin{gathered}
P\left(v^{*}\right)=\frac{1}{2} \operatorname{erfc}\left[\frac{v^{*}-\langle v>}{(2 \beta<v>k T)^{1 / 2}}\right] \\
\operatorname{D\sim P}\left(v^{*}\right)
\end{gathered}
$$

where $\langle v\rangle$ is the average segment volume, $\beta$ is the isothermal compressibility of the polymer and erfo is the complementary error function.

Although both of these theories in their original formulations did not consider the diffusion a small molecule in a polymer, they have been successfully applied to such systems. Fujita ${ }^{29}$ has demonstrated that the Cohen-Turnbull theory adequately describes the temperature dependence of diffusion in polymers in several systems. (Acutally Fujita used an empirical equation for $D$ due to Doolittle 30 which is equivalent to the Cohen-Turnbull equation for D). Fujita 29 and others ${ }^{31-33}$ have shown that the Cohen-Turnbull theory, properly modified, adequately accounts for the concentration dependence of D up to $10 \%$ of diffusant. Kumins and Roteman 34 have used Bueche's theory successfully to correlate the diffusion behavior of small gas molecules with their van der Wal volumes. 
However, the success of both theories must be viewed as being primarily correlative rather than truly predictive.

Recently Sanchez 35 obtained the following expression for the diffusion of a small molecule in a polymer:

$D_{0} \equiv D(c=0)=\frac{\bar{u}}{6}\left(v^{*}\right)^{1 / 3} \operatorname{erfc}\left[\frac{v^{*}-\bar{v}^{-\infty}}{\left(2 B \bar{v}^{-\infty} k T\right)^{1 / 2}}\right]$

where $\bar{V}^{-\infty}$ is the partial molar volume of the diffusant in the limit of zero concentration, $\beta$ is the compressibility of the polymer, and all other symbols have the same meaning as before. Equation (19) can also be suitably modified to treat the diffusion of a large molecule composed of $N$ segments, each of which is able to execute independent diffusive motions.

Although Eq. (19) has yet to be tested quantitatively, it has the potential of being a predictive theory of diffusion. It is predictive in the sense that all of the requisite parameters and variabies can be determined independently from other physical data; $v^{*}$ can be determined from viscosity or self-diffusion data on the pure liquid diffusant; $\bar{V}^{-\infty}$ can be semi-quantitatively calculated using either the Flory ${ }^{2-4}$ or lattice fluid ${ }^{5}$ theory of solutions; and $\beta$ can be determined either experimentally or theoreticaliy.

The attractive property of Eq. (19) is that it embodies all of the physical factors judged important for diffusion in polymers through $v^{*}, \bar{v}^{-\infty}$, and $B ; v^{*}$ is a unique property of the shape and size of the diffusant; $\bar{v}^{\infty}$ is a property which depends sensitively on the polymer-diffusant intermolecular 
interaction; and : of course, is a characteristic property of the polymer.

Qualitatively, Eq. (19) also explains why the diffusion of a small molecule decreases by 4 or 5 orders of magnitude in a polymer. This can best be illustrated by expanding erfc $X$ in an asymptotic series ${ }^{36}$ so that Eq. (19) becomes (valid for large $x$ ):

$D_{0} \simeq \frac{\bar{u}}{6} \frac{\left(2 \beta v^{-\infty} k T / \pi\right)}{v^{\star}-v^{-\infty}}\left(v^{*}\right)^{1 / 3} \exp \left[-\frac{\left(v^{*}-v^{-\infty} i^{2}\right.}{2 \beta \bar{v}^{-\infty} k T}\right]$

The equation for the self-diffusion constant $D_{d}$ of the diffusant will be the same as Eq. (19) or (20) except that $\bar{v}^{-\infty}$ is replaced by the molar volume $v_{d}$ of the diffusant and $\beta$ is replaced by the compressibility $\beta_{d}$ of the diffusant. Compressibilities of polymer liquids are just about one order of magnitude smaller than those of similar low molecular weight liquids. Thus, the big difference between $D_{d}$ and $D_{0}$ is the compressibility of the medium in which the diffusant molecule finds itself. (Volume fluctuations are directly proportional to $\beta$ ). Decreasing $\beta$ by an order of magnitude can diminish D by a substantially larger amount since $B$ appears in the exponential.

3. Diffusion below $T_{g}$

Analysis of migration or diffusion in polymers is often based on ideal conditions. That is, the diffusion constant is assumed to be constant independent of the concentration of the diffusing material in the polymer and the concentration in the polymer is assumed to be given by Henry's Law 
at equilibrium, where $p$ is the pressure of the diffusant

in the gas surrounding the polymer or the concentration of the diffusant in a solution surrounding the poiymer. However for some polymeric systems, especially glassy polymers, these conditions do not hold, so that a more complicated analys is is required.

Vieth $^{37}$ and others have studied diffusion and sorption in systems in which Eq. 21 is not obeyed. An exampie of such a system is methane in orientated polystyrene. The slope of the solubility versus pressure is not constant as in Eq. 21, but decreases with pressure and becomes constant at high pressures. Vieth and coworkers postulated that two modes of sorption are operative in such systems. The first mode of sorption, $C_{D}$, is proportional to the pressure, while the second mode of sorption, $C_{H}$, obeys Langmir sorption. Thus at equilibrium,

$C=C_{D}+C_{H}=k_{D} P=\frac{C^{\prime} H^{b p}}{1+b p}$

The second mode of sorption, $\mathrm{C}_{H}$, is considered to be due to holes or voids in the polymer. Methods have been given 37 to determine the constants $k_{D}, b$ and $C_{H}{ }^{l}$ in Eq. 22 from sorption curves. It was demonstrated that the equilibrium gas solubilities in glassy polymers may be characterized by the dual sorption model mathematically expressed by Eq. 22. 
Vieth and 5 ladek ${ }^{38}$ developed a theory of diffusion in

systems that have dual sorption. They assumed the concentration

in the Langmuir isotherm, $C_{H}$, of the adsorption did not

contribute to diffusion and that the diffusion constant $D$

of $C_{D}$, the Henry's law isotherm, is independent of concentration.

They obtained the diffusion equation

$$
D \frac{\partial^{2} C_{D}}{\partial x^{2}}=\frac{\partial^{C_{D}}}{\partial t}\left[1+\frac{C_{H}{ }^{\prime} b / k_{D}}{\left(1+b C_{D} / k_{d}\right)^{2}}\right]
$$

and applied Eq.23 to transient sorption of $\mathrm{CO}_{2}$ in

Mylar. Eq. 23 could not be analytically solved for the boundary conditions of transient sorption because it is not linear in $C_{D}$. Therefore, numerical solutions of Eq. 23 were obtained for assumed values of $b, C_{H}$ and $k_{p}$. A method was given for matching these theoretical curves to the experimental sorption curves to obtain the diffusion constant D. Good agreement with the observed absorption was obtained. The method has since been applied to other systems exhibiting dual sorption.

Paul and Kemp ${ }^{39}$ have investigated time lag experiments for systems exhibiting dual sorption. While Eq. 23 cannot be solved analytically for the boundary conditions (Barrer conditions) used for time lag experiments, analytic expressions for the permeability and time lags were derived. Kemp ${ }^{40}$ made time lag experiments on a membrane of a silicone rubber impregnated with molecular sieve particles. Becasue the molecular sieve particles exhibited large Langmuir adsorption of the gases used, the membrane exhibited dual sorption. 
He was able to determine the constants $b, C_{H}^{\prime}, k_{D}$ and $D$ from measurements of the silicone rubber and molecular sieves and predict the results of the time lag experiments. Good agreement was obtained.

The time lag experiment may be used to determine if a material obeys ideal diffusion. Fig. I shows the amount of $\mathrm{CO}_{2}\left(A Q_{t}\right)$ diffused through a membrane versus the time. At times greater than 100 minutes, the amount increases linearly with time with a slope, transmission coefficient, of $P=0.1564 \mathrm{cc} / \mathrm{min}$. Extrapolating this 1 inear relationship (dashed curve) to $A Q_{t}=0$ gives a time lag of 81 minutes. The amount of $\mathrm{CO}_{2}$ versus time that would diffuse through the membrane for ideal diffusion with these values of the transmission coefficient and time lag has been computed and is shown by the crosses. This curve is far from the experimental curve indicating that diffusion of $\mathrm{CO}_{2}$ in this membrane is not idea1. In fact, the membrane is one made by Kemp to have strong dual sorption. Thus, examination of the time lag curve of a membrane may be used to determine if the system shows ideal diffusion.

A simple test of ideal diffusion from a time lag experiment may be made as follows. Determine the transmission coefficient $T$ and time $\operatorname{lag} \theta$ for the system. Then for ideal diffusion, the amount of gas that has diffused through the membrane at a time equal to the time $\operatorname{lag} \theta$ is given by $0.3343 \theta T$.

If the amount of gas at the time lag differs from this value, the system does not exhibit ideal diffusion. For the case discussed, we obtain $0.3343 \times 81 \times 0.1564=3 \mathrm{cc}$. Since the experiment gives 1 cc, the system does not obey ideal diffusion. 


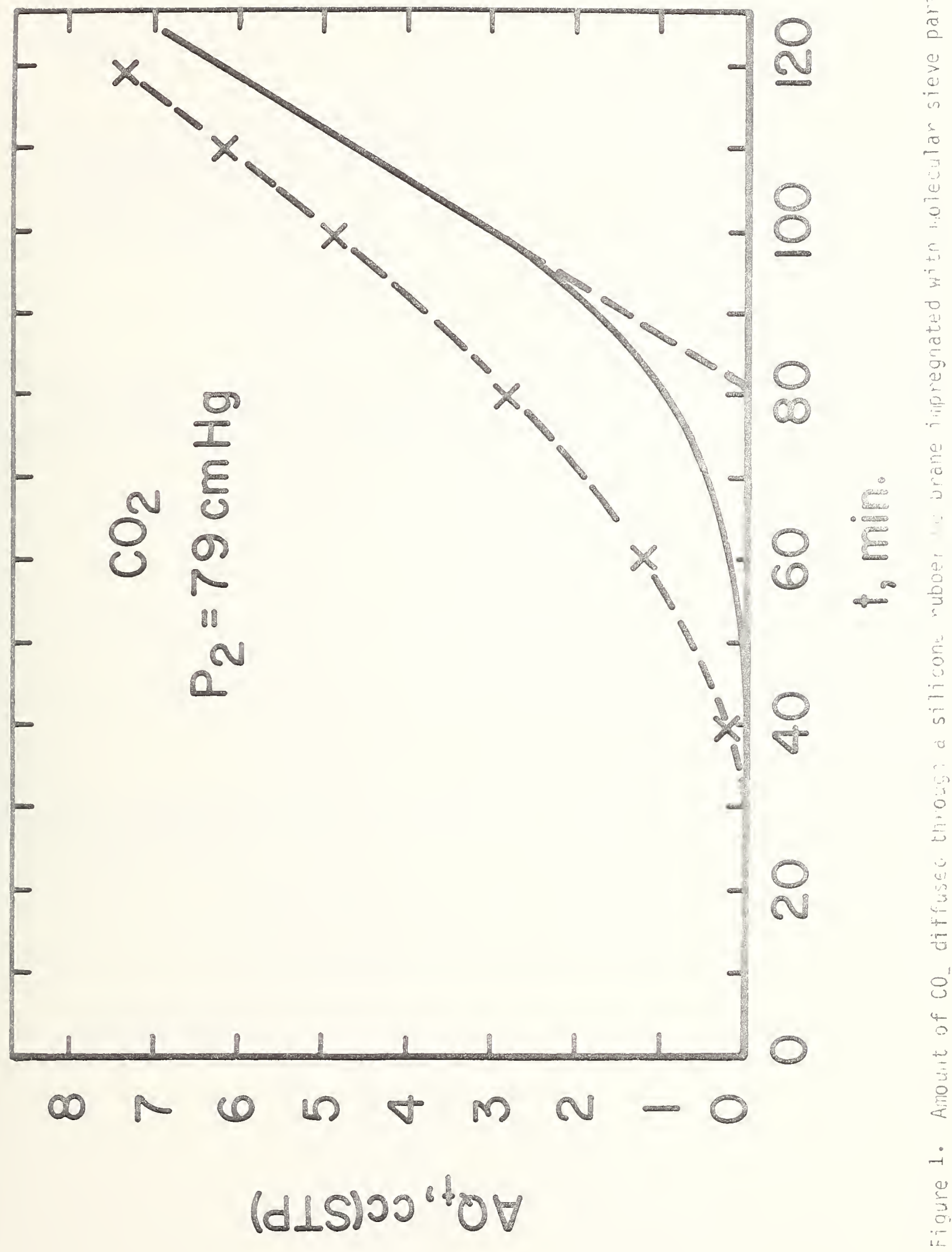


G. IISCELLANEO IS

$N, N^{\prime}$ - Diphenyl thiourea (thiocarbanilide)

$0.5 / P \mathrm{~V} \quad(\mathrm{c})$

Cyanoguanidine (Dicyandiamide)

$1 / \mathrm{PO}$

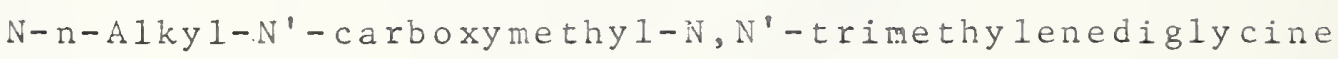
$R=C_{14}-C_{18}$

$1.35 / N R$

$p-t$-Amylphenol- Formaldehyde Resins

$2.1 / \mathrm{PA}$

Nylon 66/610/6 terpolymer

$1.5 / \mathrm{PON}$

Poly (1,4-cyclohexylenedimethylene-3, $3^{\prime}$ thiodipropionate) partially terminated with stearyl alcohol, MW1800-2200

$0.5 / P P / .005$ 


\section{PHENOLS (continued)}

\section{Tetra- :}

Tetrakis [ methylene $(3,5-d i-t-b u t y I-4-h y d r o x y-$ bydrocinnamate)] methane Irganox 1010

$$
\begin{aligned}
& .5 / P O \\
& .05 / E-1 A, E-A A / \\
& .005 \\
& .5 / P S, E-A A, E-V A C, \\
& \text { S-B, IB } \\
& 1 / P O N \\
& .5 / P O I
\end{aligned}
$$

\section{E. PHOSPHITES}

Hydrogenated 4, $4^{\prime}-i-p r o p y l i d e n e$ diphenol-

$$
\text { phosphiteester resins 2400-3000 }
$$

4, 4'-i-Propylidenediphenol alkyl ( $\left.\mathrm{C}_{12}-\mathrm{C}_{15}\right)-$ phosphites

Tri(mixed mono- and dinonyl phenol) phosphite

$2-t-B u t y 1-a-(3-t-B u t y 1-4-$ hydroxypheny 1$)-$ p-cumenyl bis ( $p$-nonylphenyl)phosphite

Cyclic neopentanetetrayl bis (octadecyl phosphite)

\section{$1.35 / N R, B-A, A-B-S$,} $\mathrm{B}-\mathrm{S} / .004$

$0.25 / P 0$

$0.15 / \mathrm{PO}$

$0.20 / P S, P S$

F. THIO CARBOXYLIC ACIDS ANL ESTERS

Thiodipropionic Acid

Dimyristyl thiodipropionate

Dicetyl thiodipropionate

Distearyl thiodipropionate

Antioxydans AS

Advastab PS 802 


\section{References}

1) J. Crank, "Mathematics of Diffusion", 2nd Ed. Clarendon Press, Oxford (1975).

2) P. J. Flory, J. Amer. Chem. Soc., 87, 1873 (1965).

3) B. E. Eichinger and P. J. Flory, Trans. Faraday Soc., 64, 2035 (1968).

4) P. J. Flory, Discuss. Faraday Soc., 49, 7 (1970).

5) I. C. Sanchez and R. H. Locombe, J. Phys. Chem, 80, 2352, 2568 (1976).

6) P. J. Flory, "Principles of Polymer Chemistry", Cornell Univ. Press, Ithaca, NY (1953).

7) J. R. Conder and J. H. Purne17, Trans. Faraday Soc., 65, 839 (1969).

8) N. F. Brockmeier, R. W. McCoy and J. A. Meyer, Macromolecules. 5, 130 (1972).

9) H. Purne11, "Advances in Analytical Chemistry and Instrumentation", Vol. 2, John Wiley \& Sons, New York (1973).

10) D. C. Bonner and N. F. Brookmeier, Ind. Eng. Chem., Process Des. Dev. 16, 180 (1977).

11) I. C. Sanchez and R. H. Lacombe, J. Poly. Sci. Polym. Letters Ed., 15, 71 (1977)

12) I. C. Sanchez, "Polymer Blends", edited by D. R. Paul and S. Neuman, Vol. 1, Academic Press, New York (1978).

13) G. Delmar, D. Patterson, and T. Somcynsky, J. Polym. Sci, 57, 79 (1962).

14) B. E. Eichinger and P. J. Flory, Trans. Faraday Soc., 64, 2061 (1968).

15) P. J. Flory, J.L. Ellenson and B. E. Eichinger, Macromolecules, I, 279 (1968).

16) B. E. Eichinger and P. J. Flory, Trans. Faraday Soc., 64, 2061 (1968).

17) B. E. Eichinger and P. J. Flory, Ibid., 64, 2053 (1968).

18) M. J. Hayes and G. S. Park, Ibid, 51, 1134 (1955).

19) A. Aitken and R. M. Barrer, Ibid, 51, 116 (1955).

20) S. Prager, E. Bagley and F. A. Long, J. Amer. Chem. Soc., 75, 1255 (1953).

21) H. Fujita, A. Kishimoto, and K. Matsumoto, Trans. Faraday Soc. 56, 424 (1960).

22) H. Fujita, "Diffusion in Polymers", ed. by J. Crank and G. S. Park, Academic Press, NY

23) I. Auerback, et. al., J.Polym. Sci., 28129 (1958).

24) R. K. Ghai, H. Ert7, and F. A. L. Dut7ien, AICHE Journal, 19, 881, 1215 (1973).

25) Chapter 4 in reference 22

26) M. H. Cohen and D. Turnbu17, J. Chem. Phys., $\frac{31}{-54-}, 1164$ (1959). 
27) D. Turnbuill and M. H. Cohen, Ibid, 52, 3038 (1970).

28) F. Bueche, Ibid, 21, 1850 (1953).

29) H. Fujita, Fortschi. Hochpolym. - Forsch., 3, 1 (196i).

30) A. K. Doolittle, J. Appl. Phys., 22, 1471 (7951), 23236 (1952).

31) A. Kishimoto and Y. Endu, J. Polym. Sci. A. ;, 1799 (1963).

32) A. Kishimoto, Ibid, $\underline{2}, 1421$ (1964).

33) A. C. Newns, Trans. Faraday Soc. 59, 2150 (1963).

34) C. A. Kumins and J. Poteman, J. Polym. Sci., 55, 699 (1961).

35) Unpublished calculations of I. C. Sanchez.

36) "Handbook of Mathematical Functions", M. Abramowitz and I. A. Stegun editors, Dover Publications, New York (1965) p. 298.

37) W. R. Vieth, J. M. Howell and J. H. Hsieh J. Membrane Sci., I, 177 (1976) and references given therin.

38) W. R. Vieth and K. J. Slakek, J. Col7. Sci, 20, 1014 (1965).

39) D. R. Kemp and D. R. Paul J. Polm. Sci., Part A-2, 12, 485 (1974).

D. R. Paut and D. R. Kemp J. Polm. Sci, Part C, 41, 79 (1973).

40) D. R. Kemp, "The Diffusion Time Lag in Heterogeneous Polymer Membranes" Dissentation, the University of Texas, (1972). University Microfilms Ann Arbor, Mich. No. 73-466. 
Introduction

A list of libs approved addli lves (Section 178) for plastics lo be used in contact with food are classifled as to their chemical characteristics, along with their maximum allowable amounts (\%)/ in particular types of plastics/and the maximum thickness of the plastics in inches.

\section{Classification}

A. ALCOHOLS AND ESTERS

1,3 - Butanediol

Pantaerythritol

$0.4 / \mathrm{PVC}$

Pantearythritol stearate

$0.4 / P V C$

B. BENZOPHENONES

$2-$ Hydroxy-4-n-octoxy-benzophenone $0.5 /$ PO Advastab 46

Cyasorb UV5 31

2-Hydroxy-4-i-octoxy-benzophenone Methanone [2-Hydroxy-4-(i-octoxy) pheny 1 ] pheny 1

$0.5 / \mathrm{PO}(\mathrm{c})$

C. METALLIC SALTS

1. CALCIUM:

benzoate

myristate

ricinoleate

1/POM(c)

stearate

2. COPPER:

cupric acetate

$.025 / N Y 66 / .0012$

cupric carbonate

$.005 / N Y 66 / .0015$

cuprous bromide

$.0175 / N Y 66 / .0015$

cuprous iodide

$.0025 / N Y 66 / .0015$

3. LITHIUM:

iodide

$.065 / \mathrm{NY} 66 / .0012$

4. MAGNESIUM:

salicylate

$0.3 / \operatorname{RPVC}(\mathrm{c})$

5. POTASSIUM:

bromide

$0.18 / \mathrm{NY} 66 / .0015$ 
6. TIN :

$$
\begin{aligned}
& \text { Di-n-octyl-tin maleate polymer PVC } \\
& \text { Di-n-octyl-tin-bis ( } i-o c t y l m e r c a p t o- \\
& \text { acetate) PVC } \\
& \text { Poly }[(1,3-d i-b u t y 1-d i-S t a n n- \\
& \text { thianediylidene) 1,3-dithio] } 0.2 / \mathrm{PVC}
\end{aligned}
$$

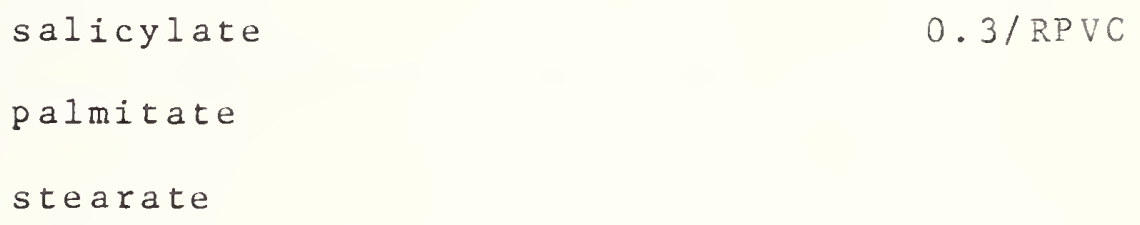

7. ZINC: dibutyldithiocarbamate $0.2 /$ IB-IP(c)

\section{PHENOLS}

\section{Mono- :}

$2,6-\mathrm{Di}-t-\mathrm{b}$ uty $1-p-\mathrm{cresol}$

Ionol

BH T

Advastab 401

$2,6-D i-t-b$ utyl-4-e thyl-phenol Antioxidant 724

$2,6-B$ is ( 1 -methy Iheptadecyl)-p-cresol

4-Hydroxy nethy $1-2,6$-di-t-butyl phenol

$n$-Octadecyl-3-(4'-hydroxy-3' $5^{\prime}-$ di-t-butyl phenyl) .25/po/.0025 propionate

Octadecyl-3,5-di-t-buty 1-4-hydroxy-hydrocinnamate . 25/PS, PS

Irganox 1076

2(2'-Hydroxy-5'-methyl phenyl)benzotriazole Tinuvin $\mathrm{P}$

$2\left(3^{\prime}-t-B u t y 1-2^{\prime}-\right.$ hydroxy $-5^{\prime}-$ methylpheny 1$)-5-$ chlorobenzotriazole Tinuvin 326

Butyrated styrenated cresols
$.5 / A-B-S$

$.25 / P V C(c), P S$

$.5 / \mathrm{PO}$

$.5 / \mathrm{PS}, \mathrm{PO}$ 
Di- :

$$
\begin{aligned}
& \left.4,4^{\prime} \text { - Me thylene-bis ( } 2,6-d i-t-b u t y l p h e n o 1\right) \\
& \text { Antioxidant } 702 \\
& \text {. } 25 / \text { PHC resins, } \\
& \text { turpene resins } \\
& .5 / P E, P B \\
& 2,2^{\prime} \text {-Methylene-bis }(6-t-b u t y 1-4-e t h y l p h e n o 1) .6 / A-B-S \\
& \text {. IPA } \\
& 2,2^{\prime} \text {-Methylene-bis (4-methyl-6-t-butylphenol) . 1/Po } \\
& 1 / \mathrm{POM}(\mathrm{C}) \\
& .5 / \mathrm{POM} \\
& 4,4^{2}-\text { Butylidene-bis }(4-t-b \text { uty } 1-m-c r e s o 1) \quad .5 / P P \\
& .3 / \mathrm{PE} \\
& 4,4^{\prime}-\text { Thio-bis }(6-t-b u t y 1-m-c r e s o l) \\
& .25 / P E
\end{aligned}
$$

$2,6-B$ is $(2-$ hydroxy-3-nony $1-5$-methy 1 -benzy 1$)-p-\operatorname{cresol} A-B-S$

Tris (2-methy 1-4-hydroxy-5-t-butylpheny 1 ) but ane

$.25 / A-B-S$

$.1 / \mathrm{A}-\mathrm{B}-\mathrm{S}$

$.2 / \mathrm{PS}$

$1,3,5-\operatorname{Tr}$ imethy $1-2,4,6-t \mathrm{ris}-$

$(3,5-d i-t-b u t y 1-4-h y d r o x y b e n z y l) b e n z e n e$ Ionox 330, Antioxidant 330

1, j, 5-Tris (3,5-di-t-buty 1-4-hydroxy-hydrocinnamoy 1 ) hexanydro-s-triazine

.5

$1 / N Y$

$.25 / P P$

$.1 / \mathrm{PE}$

$.5 / \mathrm{E}-\mathrm{P}-\mathrm{EN} /$ $.005 / .005$

$1,3,5-\operatorname{Tris}(3,5-\mathrm{di}-t-b u t y 1-4-$ hydrobenzy 1$)-$ $5-t$ riazine $-2,4,6(1 \mathrm{H}, 3 \mathrm{H}, 5 \mathrm{H})$ trione

$.25 / P P$

$.1 / \mathrm{PE}$

$.5 / P E$

$.5 / \mathrm{E}-\mathrm{P}-\mathrm{EN} /$ .005 


\section{AEBREVIATIONS FOR POLYMERS}

AA Acrylic Acid

A Acrylonitrile

B Butadiene

(C) Copolymer

E Ethylene

EN b-Ethylidine-2-norbornene

IB Isobutylene

IP Isoprene

$1 \mathrm{~A}$ Yethacrylic Acid

NR Natural rubber

NY Nylon

P Propylene

PA Polyamide

PBD Polybutadiene

PE Polyetinylene

PHC Petroleum hydrocarbon

Po Polyolefin

POM Polyoxymethylene

PP Polypropylene

PVC Poly(vinyl chloride)

S Styrene

VAC Vinyl acetate 
Molecular Models of Some of the Additives

$(0.7 \mathrm{~nm}$ or $7 \AA$ is represented by $1.2 \mathrm{~cm}$ of the model) 


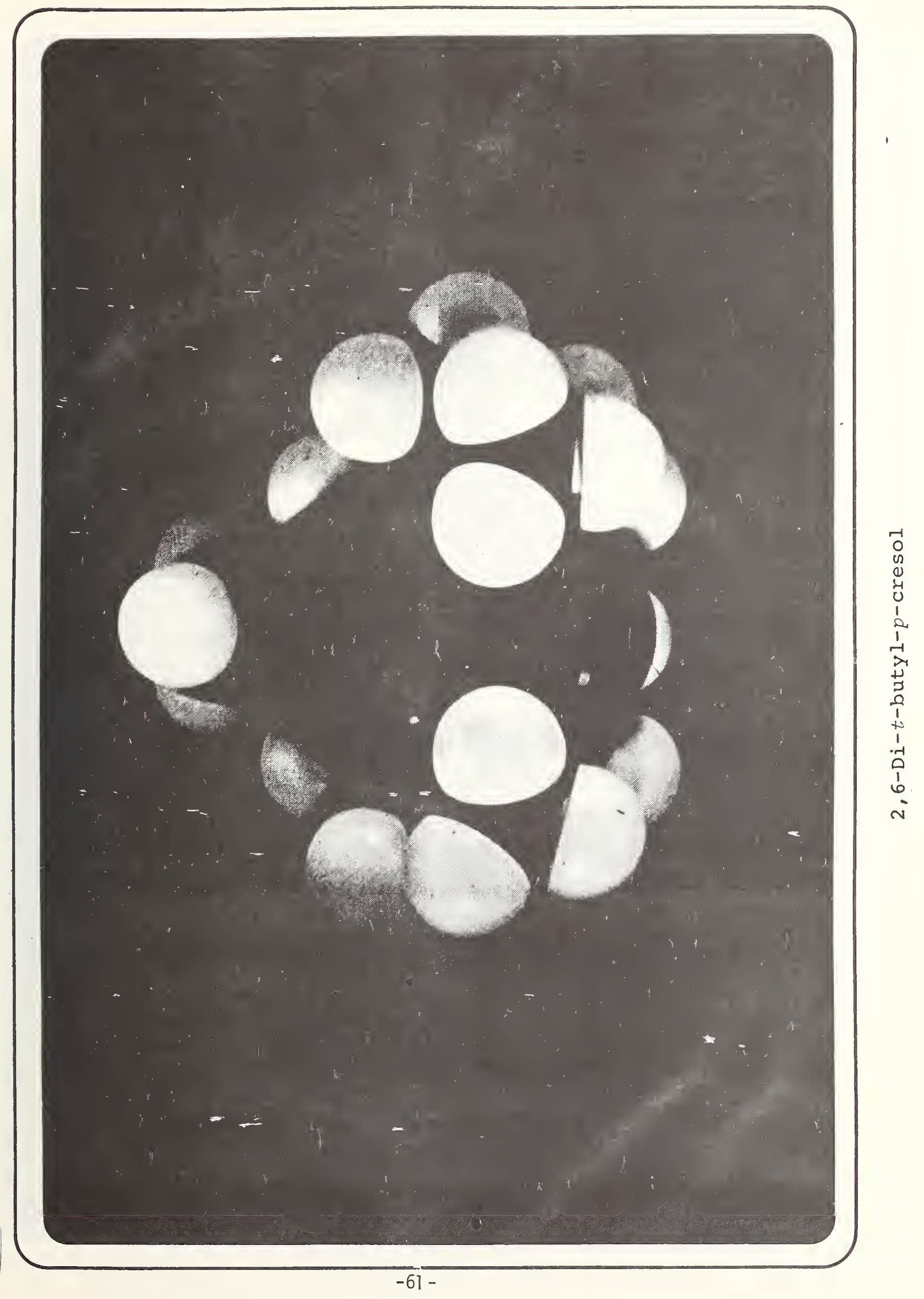



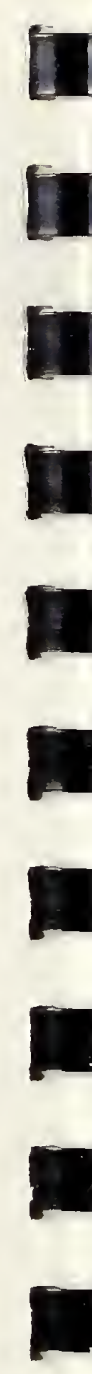

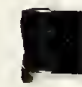

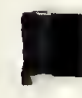

.

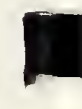

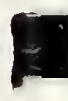

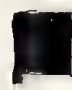

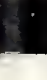

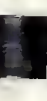




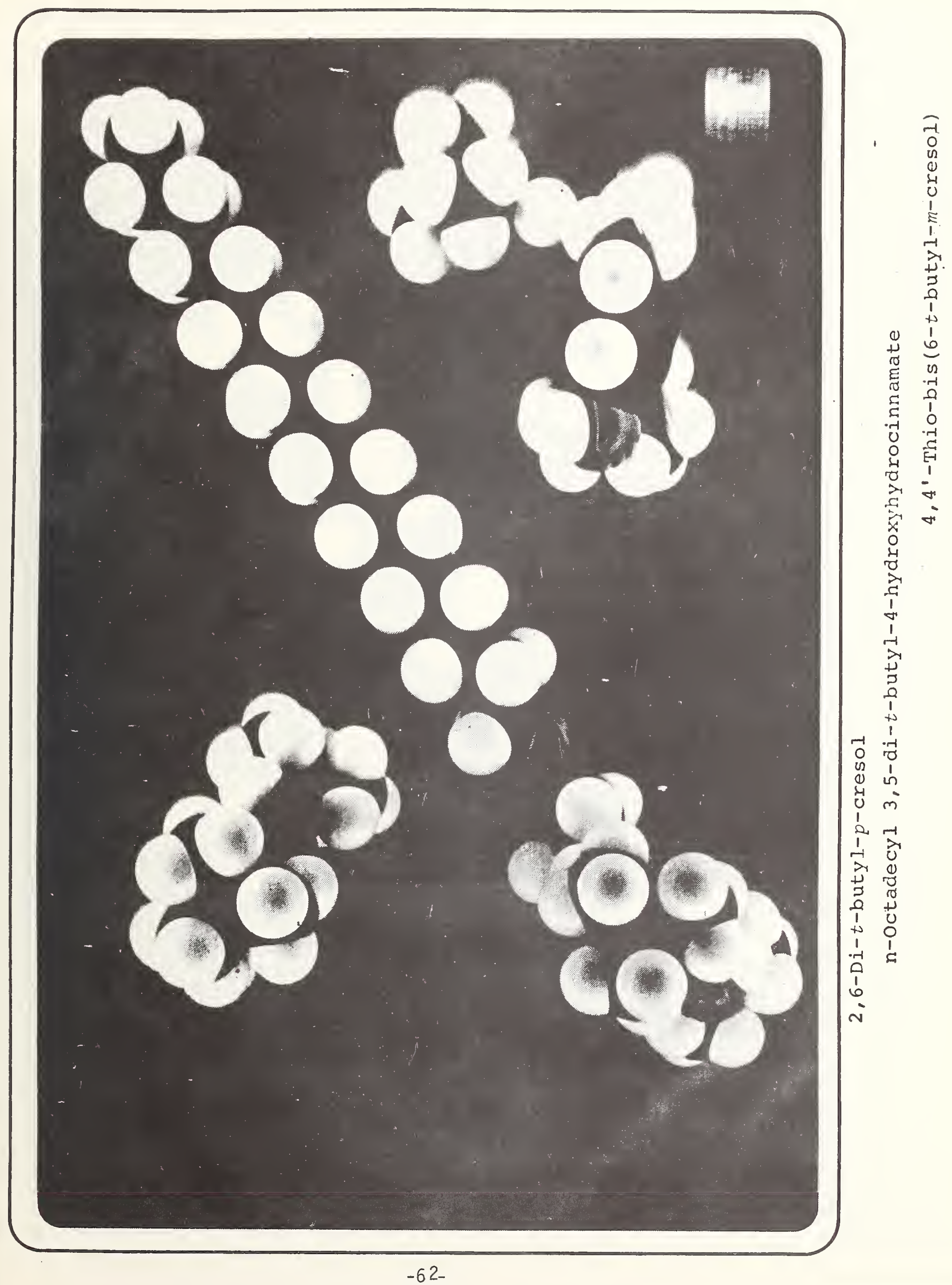


.

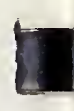

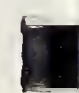

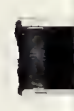

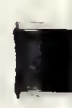

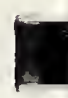

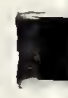

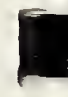

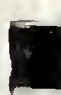

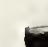

.

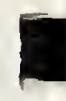

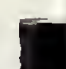

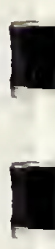

$F$

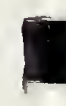

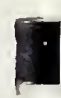

1 


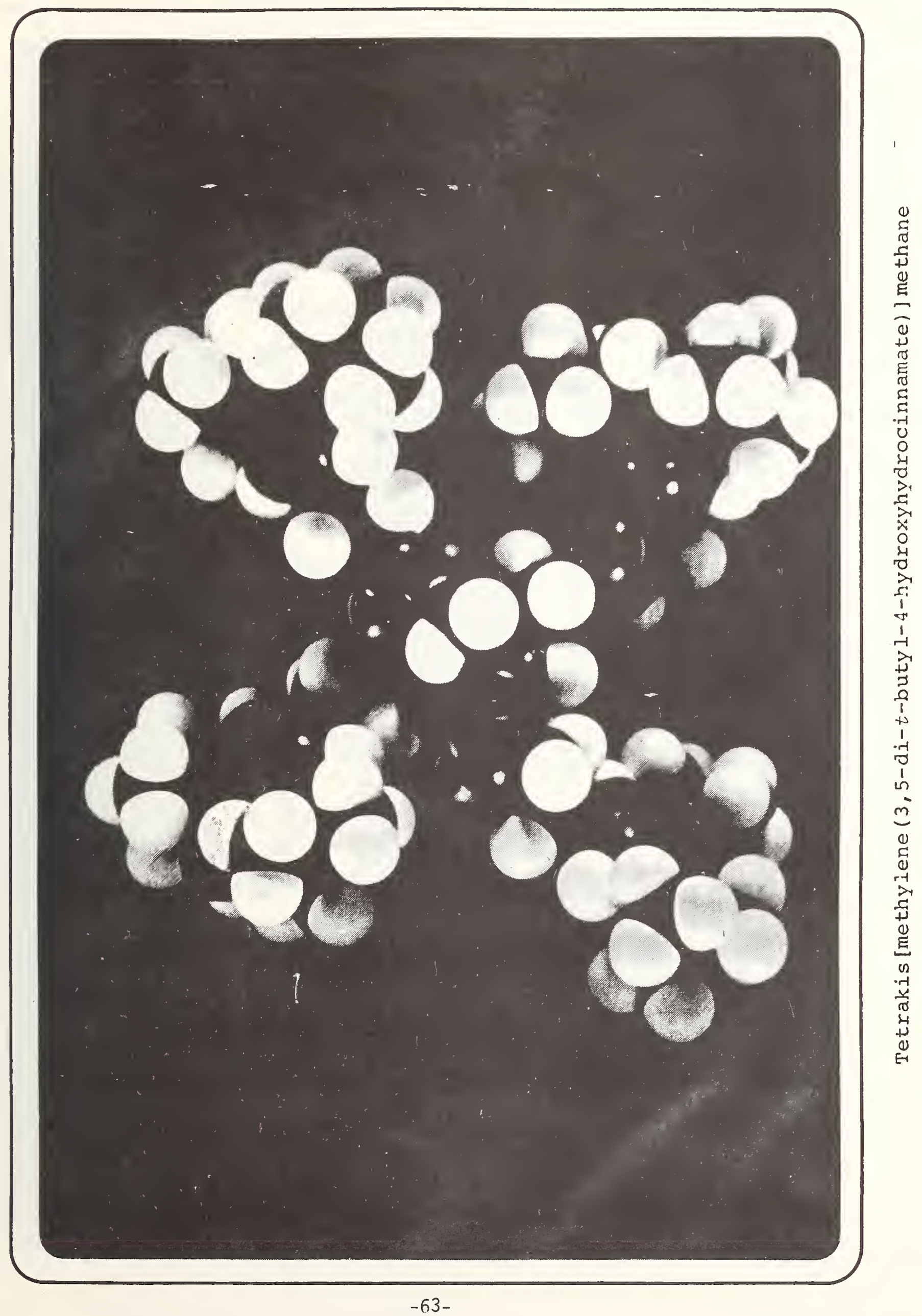




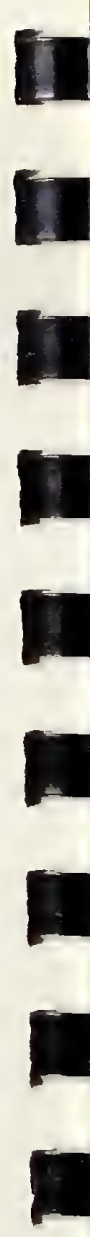

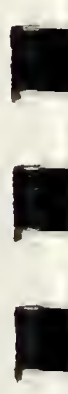

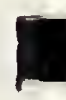

.

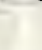

.

,

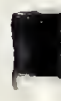

8

3 


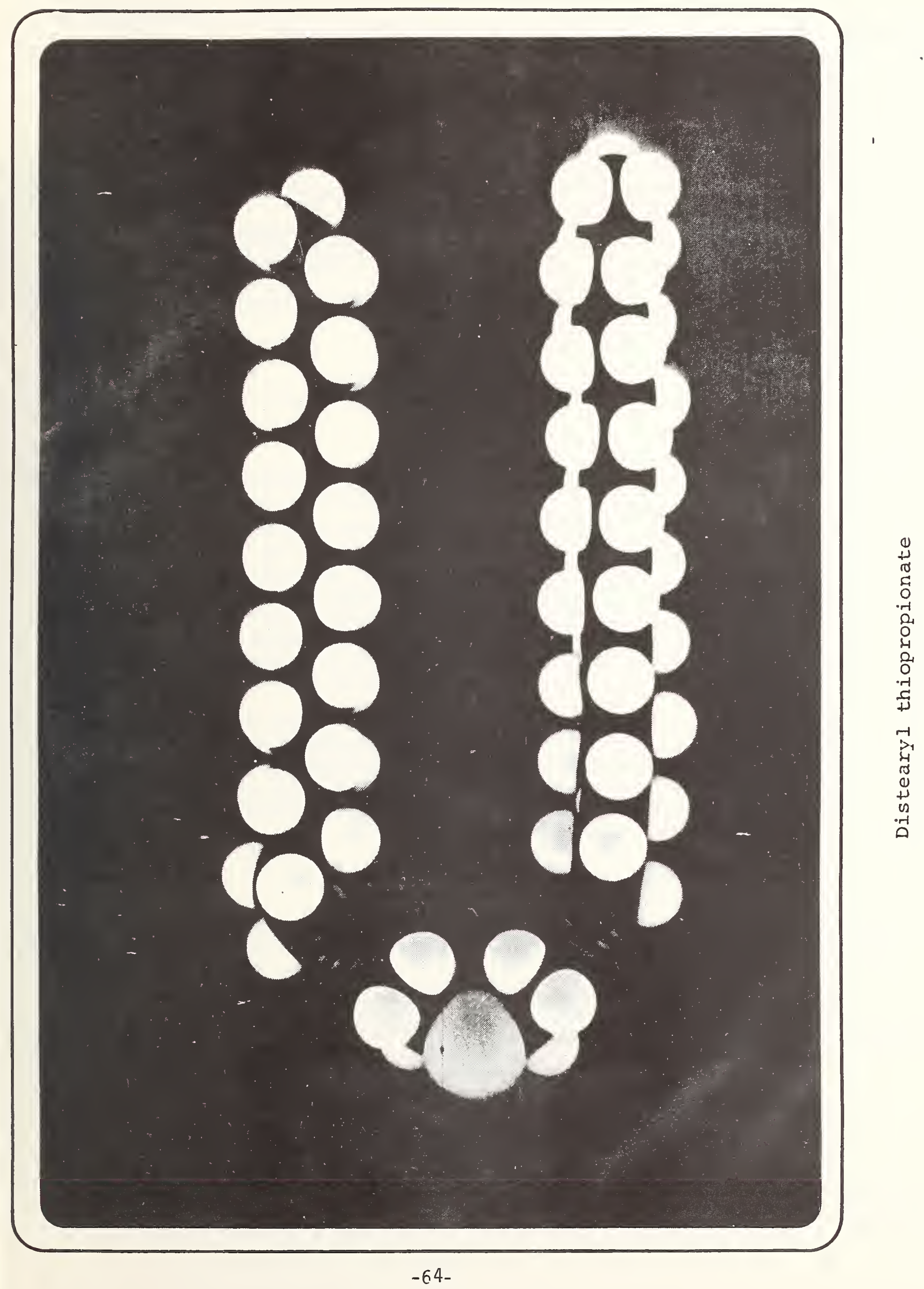




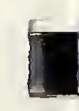
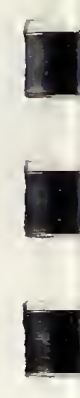

.

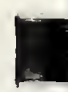

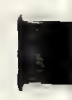

.

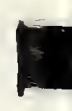

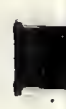

.

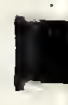

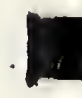

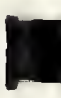

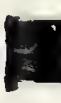

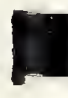

11

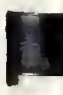


NBS.IIUA IKEV ,., H)

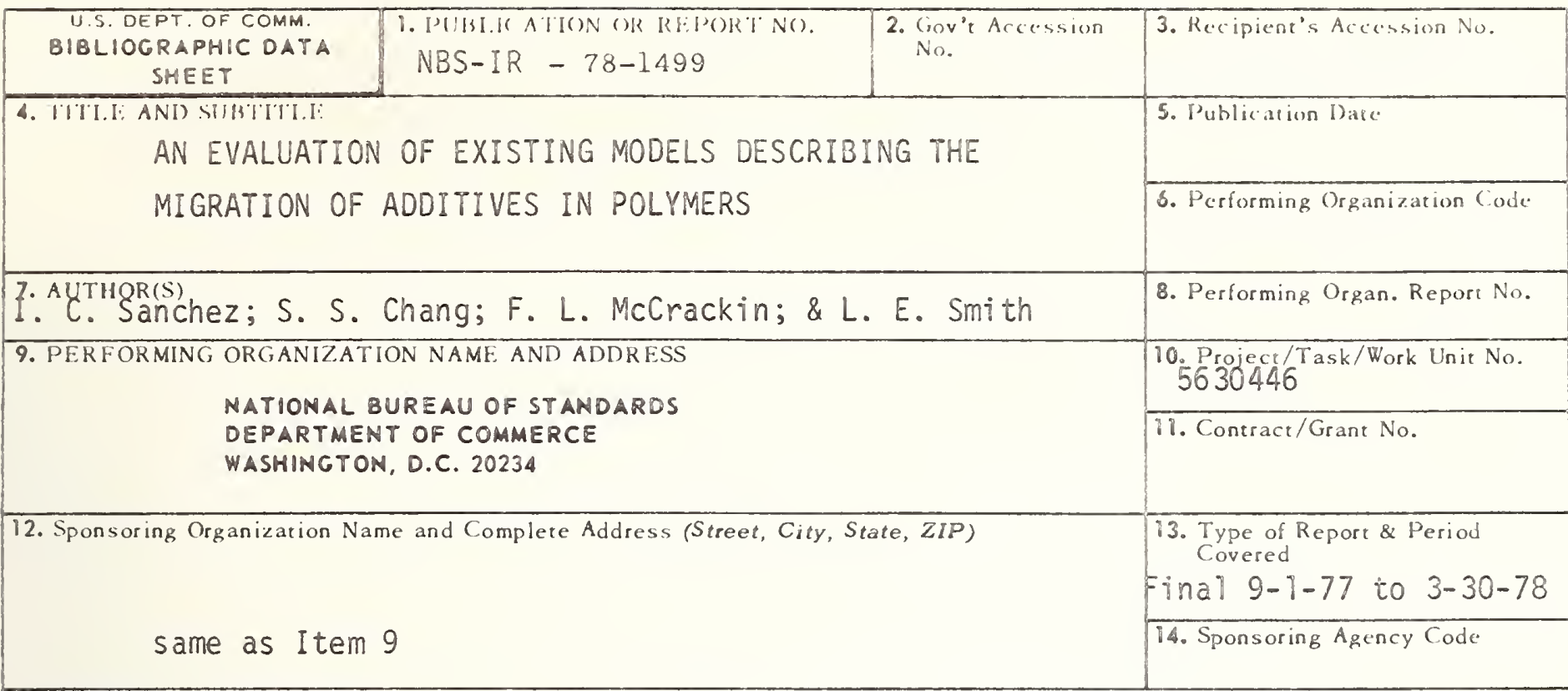

16. ABSTRAC'T (A 200-word or less factual summary of most significant information. If document includes a significant bibliography or literature survey, mention it here.)

The objective of this work is the development of mathematical modeis that describe the migration of a variety of small molecules in polymers that have applications in food contact uses. In the most general cases, these models will be able to predict the amount of additive migration given any particular time and temperature history. These models can serve as the technical basis for more efficient regulatory methods under existing frameworks or in the design and implementation of new indirect additive regulations or policy.

The first steps in the development and assessment of such mode is are given in this report. The first section presents a preliminary survey of migration data applicable to food contact situations that are available in the current iiterature. The second section surveys available models describing migration and evaluates their present and potential utility.

17. KEY WORI)S (six to twelve entries; alphabetical order; capitalize only the first letter of the first key word unless a proper name; separated by semicolons)

Additives; diffusion; food additives; indirect additives; migration; models; regulation
18. AVAII.AIBILITY
Xnlimited

[? For Official Distribution. Do Not Release to NTIS

[] Order From Sup. of Doc., U.S. Government Printing Office Washington, D.C. 20402, SD Cat. No.C13

${ }_{\mathrm{X}}^{-}$- Order I rom National Technical Information Service (NTIS) Springficld, Virginia 22151

\begin{tabular}{|c|c|}
\hline $\begin{array}{l}\text { 19. SECURITY CLASS } \\
\text { (THIS REPURT) }\end{array}$ & 21. NO. OF PAGES \\
\hline UNCL ASSIF IED & 70 \\
\hline $\begin{array}{l}\text { 20. SECURITY CLASS } \\
\text { (THISPAGE) }\end{array}$ & 22. Price \\
\hline UNCLASSIFIED & $\$ 5.25$ \\
\hline
\end{tabular}



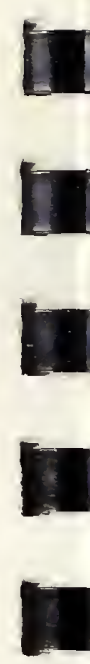

A
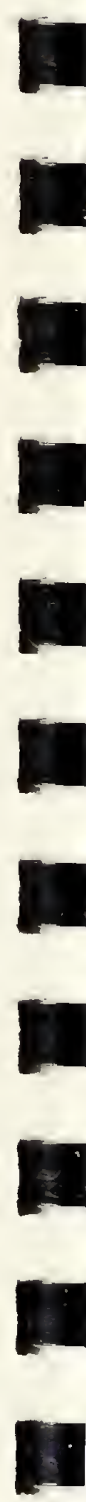

1 


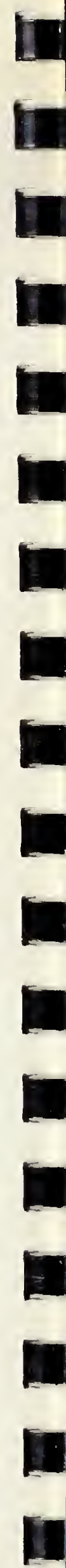